\title{
Autonomía como potencia: el actuar reflexivo que produce sentido
}

Una de las hipótesis que sostengo es que la autonomía es una manifestación explícita de lo político. La autonomía surge en lo cotidiano, es fruto de la búsqueda de sentido de las prácticas que cotidianamente experimentamos. Ante todo, la autonomía es consecuencia del proceso reflexivo que se instala en la subjetividad y a partir del cual se estructura la existencia. Por eso, para Castoriadis la autonomía es un proyecto, y no está establecida, sino que se constituye como potencia de la condición humana, es decir, potencia de creación e invención que está vinculada estrechamente con la idea de imaginación y la lógica del imaginario.

Ya que la creación supone, tanto como la alienación, la capacidad de darse lo que no es (lo que no es dado en la percepción, o lo que no es dado en los encadenamientos simbólicos del pensamiento racional constituido). Y no puede distinguirse el imaginario que entra en juego en la creación de lo imaginario "puro y simple", diciendo que el primero "se anticipa" a una realidad aún no dada, sino que "se verifica" a continuación. [...] lo esencial de la creación no es "descubrimiento" sino constitución de lo nuevo: el arte no descubre, constituye; y la relación de lo que constituye con lo "real", relación seguramente muy compleja, no es en todo 
caso una relación de verificación. Y, en el plano social, que es aquí nuestro interés central, la emergencia de nuevas instituciones y de nuevas maneras de vivir, tampoco es un "descubrimiento", es una constitución activa. (Castoriadis, 1983, p. 231)

Es decir, la autonomía está vinculada a un principio de creación que se constituye en la capacidad latente de los agentes, de instaurar prácticas o sentidos posiblemente de una forma contingente respecto al sistema que las contiene, y que se van configurando simbólicamente a través del lenguaje y de las prácticas que reafirman dicha enunciación.

Asimismo, se puede entender como producto del discurso con su capacidad de simbolización y transformación, como encarnación que se configura primariamente en el ámbito de lo individual, pero que tiene implícito un horizonte colectivo, acorde a unas características histórico-sociales específicas. En la perspectiva de Castoriadis, la autonomía se inscribe como germen de las significaciones imaginarias que organizan e instituyen lo social, y se instala en esa posibilidad abierta de dotar de significación al mundo, a la sociedad y al ser mismo. Se anida justamente en las potencialidades del lenguaje y el discurso en el cual se configura el mundo de la significación, "que es indisociablemente principio de existencia, principio de pensamiento, principio de valor, principio de acción” (1988, p. 178).

Es justamente en ese vértice de lo histórico-social donde emerge el sentido, y a partir de esto se les confiere significación a las cosas, a los actos, a lo que se puede nombrar e imaginar, insertándolas en relaciones de sentido que produce lo social. Es en esta cadena de significaciones imaginarias donde la autonomía surge como germen, como potencia, como posibilidad del lenguaje de instaurar mundos inéditos de enunciación, de acción, a partir de la reflexión o problematización frente a lo real, frente a las estructuras, a las formas que designan u organizan el mundo de lo visible, de lo decible, de lo imaginado. Esta es una operación que se produce en lo cotidiano, inicialmente a nivel individual, justamente cuando los agentes se preguntan por qué las cosas son como son, por qué no pueden ser de otra forma, por qué prevalecen ciertas prácticas sobre otras, o por qué el orden que designa lo social se ha instaurado de una manera y excluye otras posibilidades. 
Es decir, cuando se interroga explícitamente la lógica de las significaciones imaginarias, en sus orígenes, y sobre todo su forma de instrumentalización u operación directamente en los sujetos, condición que los lleva a ocupar una posición o un rol delimitado.

Así las cosas, la autonomía es fruto de un proceso de autoreflexividad que opera en el sujeto y se hace posible cuando este reconoce en el contexto de lo cotidiano las condiciones instituidas de la heteronomía, sus efectos específicos en las prácticas a partir de las restricciones o limitaciones, tanto en la acción como en el discurso. Es inicialmente en el nivel del discurso donde se hace explícita esa reflexión que conduce a la autonomía; es en la apertura de crear mundo en el lenguaje donde se instala inicialmente esa potencia creadora de sentido, que opera en la praxis, pero también en el ámbito de la subjetividad.

De esta forma, la autonomía para Castoriadis es ante todo creación, crear-acción: movimiento del pensamiento y de la acción, como condición ontológica que propicia otro tipo de agente y, relacionalmente, otro tipo de sociedad en potencia.

Creación, en el ser (en lo que es, to on) surgen otras formas, se establecen nuevas determinaciones. Lo que cada vez (en cada "momento") es, no está plenamente determinado, es decir, no lo está hasta el punto de excluir el surgimiento de otras determinaciones. Creación, ser, tiempo van juntos: ser significa por-ser, tiempo y creación se exigen recíprocamente, $(1988$, p. 10)

La autonomía como momento de creación tiene una implicación directa con las circunstancias sociohistóricas que condicionan o producen al agente y lo ubican en relaciones específicas, pero atendiendo a la posibilidad siempre latente de constituir activamente otros órdenes y sentidos frente a las instituciones que determinan lo social. La autonomía es fruto de un proceso reflexivo que se ubica en unas coordenadas histórico-sociales específicas, que como proyecto engendra una posibilidad abierta de reflexión, acción y de instauración inédita de eidos nuevos. Es decir, de sentidos y significaciones frente al mundo de la vida en un enclave espacio-temporal específico. 
Ante este panorama, la intención en este capítulo es reconocer cómo las acciones de estos grupos se inscriben en el horizonte de la autonomía, a nivel individual y grupal, con el ánimo de entender un poco más el tipo de acción que ejercen y cómo esta responde a una manifestación explícita de lo político. Empiezo entonces por explicar quiénes son los que integran estos grupos, cómo están organizados, es decir, cómo toman las decisiones, qué estrategias han empleado para darle vida al grupo, y esto por supuesto establece unos tiempos y espacios para su acción, al igual que unas tensiones. La intención de dar cuenta de estas formas "particulares" de establecerse como colectivo y permite comprender cuál es el modelo de agente que se está configurando en este tipo de iniciativas, cuáles son las expectativas que van alimentando el repertorio de acciones a nivel individual, pero también como agrupación; esto necesariamente tendrá una implicación consciente en el ámbito histórico-social donde el grupo existe.

\section{La experiencia de Uno entre mil: para ser uno hay que ser todos}

UNO entre M1L, es una organización de amigos con talento, que pretende contribuir a la construcción de un modelo de vida en armonía. Es una rueda de proyectos interdisciplinares que busca articular tres elementos: Lúdica Patagógica (aprender de forma divertida, a partir de situaciones absurdas). Creatividad (pensar diferente y proponer soluciones imaginarias a problemas reales) e Inter-Acción (organización en un entorno de creación coLABORativa ${ }^{9}$ y ocupaciones felicitarias). (Uno entre mil, 2015)

9 Una de las tendencias del grupo es cambiar o jugar con la combinación de palabras y significados en función de resignificar algunas expresiones; por ejemplo, en esta palabra, no se alude solo a la idea de cooperación o colaboración, sino que se acentúa el énfasis en la palabra labor La labor para el grupo es más que un trabajo, significa la pasión por una acción que le da sentido a la vida de quien la hace, es lo opuesto a la idea convencional del trabajo. Está más cercano al concepto de labor que desarrolla Arendt. 
Este grupo busca construir un modelo de vida en armonía, que privilegie la creación y el fomento de ocupaciones felicitarias. Esto implica que los integrantes escojan cuál es el nombre que los identificará dentro del grupo y decidan cuál es la ocupación que anime su interés, que los conmueva y les permita desarrollar su talento, a partir del cual podrán encontrar su propio sentido a la vida. Este es un ejercicio inicial de reconocimiento en función de lo que cada participante realmente quiere hacer o ser.

Los que hacen parte del grupo son "lualentos", es decir, "seres con talento, lúdicos y alegres en todo, que tienen doble identidad"; esto es lo primero que oficialmente se hace cuando se es parte del grupo: decidir cómo será conocido, así es como se empieza a conectar cada agente con la realidad imaginaria que ofrece el grupo. Los que logran encontrar su luz pueden convertirse en Benjamines, o sea "seres con talento que se conectan e iluminan". Son hombres y mujeres que creen en la magia y que quieren sintonizarse con otras formas de ver y percibir el mundo a su alrededor. Son formadores de mundos posibles, diferentes a este único plano lineal y excluyente.

Dentro del grupo se establecen roles dependiendo del nivel de participación de cada persona. No se cuenta con una organización de orden administrativa estable; más bien, existe un principio de autoorganización que siempre se está transformando, se modifica con el transcurrir del tiempo y sobre todo, a partir de la dinámica que se va generando con los integrantes que van llegando. Es una estructura adaptable, con unas bases que se han construido en el camino y que se acomodan según los intereses de los que participan.

Esto fortalece una lógica de organización dinámica, en la cual cada participante está donde quiere estar, nadie está por obligación; si le gusta el juego en el que está es ahí cuando puede haber creación, de otra forma se corta la creatividad y la potencia del juego. Así, la estructura de la organización está orientada más a las posibilidades de recorrido para los participantes que a una estructura administrativa rígida.

De esta manera, Uno entre mil se nutre de la participación de los integrantes, en la medida en que cada uno va vinculándose a los diferentes talleres o laboratorios, es decir, es posible que a partir del 
recorrido que hace cada uno dentro del grupo y de su experiencia se vaya ampliando la oferta de opciones de participación. Sin embargo, la premisa básica es que el viaje es individual, es decir, cada participante decide qué quiere disfrutar dentro de la organización, con qué intensidad y qué decide ofrecer.

Este tipo de principios se construyen colectivamente y se tramitan o establecen a través de la Oficina de Soluciones Imaginarias (OsI). Así uno de los compromisos que rige durante los encuentros o apariciones es la creación colectiva en conjunción permanente con las experiencias constituidas para cada agente y que termina formando un entramado de relaciones de reconocimiento, confianza y colaboración entre los participantes.

Aquí lo que importa es el viaje, es como tú aprendes que el tema político es como tú haces la conexión, en la medida en que tú aprendes a conectarte con tu propio interno y con ese talento que tienes como ser humano es en ese momento cuando puedes entregarle a los otros y a multiplicar tu experiencia y hacer que otros brillen así como brillas tú, con tu propia luz; entonces, lo que nosotros facilitamos aquí es el proceso para que vayas aprendiendo a identificar cuáles son tus desvíos, cuáles son tus dificultades, cuáles son tus miedos, porque hacer esto no es nada sencillo, es un viaje que estamos haciendo todos, ninguno de nosotros se la sabe y cada rato nos pegamos qué embolatada [...] (Diana, 29 de marzo de 2014, entrevistada por Molina, I., Medellín)

Uno entre mil es ante todo un espacio lúdico de encuentro, de juego, de alegría, que pretende constituirse en un escenario propicio para la creación, para el disfrute, para activar los talentos de cada participante y construir a la vez una red de interacciones productivas entre saberes, prácticas, experiencias y proyectos a futuro que no están mediados por el interés económico, sino por la cooperación y la solidaridad. Dentro de las formas que ha encontrado el grupo para establecer interacciones productivas entre los participantes, se han establecido unos acuerdos básicos que dinamizan las relaciones: 
- Lo que sepa compártalo y enséñelo.

- De quien no está, solo se habla bien.

- La fluidez es permitir que las cosas se hagan, si no sabe o no puede, deléguelo; si no tiene a quien delegarlo, pida ayuda.

- Si no hay corazón es trabajo, si es trabajo es deber y la creatividad es enemiga del deber y del cronómetro.

- Imagínese la solución aún sin el problema, no pierda el hábito de asombrarse, de dudar, ide estar vivo! (Uno entre mil, 2015)

\section{Teatro por la paz: el camino por recorrer}

El Teatro por la paz, en Tumaco, empezó en 2010 con mujeres de la zona, por iniciativa de la Diócesis de Tumaco, posteriormente como fruto de la gestión de esta organización ante una ONG alemana, para recursos y profesores especializados. Empezó formalmente el trabajo con jóvenes a partir de dos grupos: Arañas y Cien pies. ${ }^{10}$ La edad de la mayoría de los participantes oscila entre los 13 y los 24 años, su nivel de formación es de secundaria y algunos empiezan sus estudios universitarios o tecnológicos. Todos los jóvenes son oriundos de Tumaco, la mayoría son afrodescendientes y han vivido en carne propia los ataques a la ciudad, las muertes selectivas, las masacres y los estragos de la violencia, es decir, las fracturas al tejido social, el miedo y el silencio como práctica normalizada, producto de la de violencia.

10 El nombre de Cien pies no es por el animal, significa que son pies que se unen para seguir trabajando por la justicia y la paz. En el caso de las Arañas, es porque son muy perseverantes, pues cuando uno ve una red de araña la destruye, pero a los pocos días ya ellas han construido otra y al construir esta red se espera que se vinculen más jóvenes para seguir trabajando por la justicia y la paz. Teste nombre es también porque en la época que se formó el grupo el barrio Nuevo Milenio (donde nacen las Arañas) no estaba bien iluminado, y los cables de la energía eran tantos que parecían una gran telaraña.(Taller con el grupo, 2014). 
El grupo juvenil era grande, pero luego algunos se salieron por diferencias entre ellos, otros se fueron por la violencia que empezó en ese momento, y otros se fueron a prestar servicio militar, entonces cada vez fue más pequeño, y yo seguí porque me gustaba mucho el teatro y me siento bien con todos los integrantes, nunca pensé que con las señoras grandes también, normalmente uno entre jóvenes con la recocha como se relaciona o como se trata es muy diferente con las señoras, pues eso era lo que yo creía, yo nunca pensé que la relación sería igual con las señoras mayores y es muy chévere. (Zulma, 10 de mayo de 2014, entrevistada por Molina, I., Tumaco)

La mayoría de estos jóvenes hacen parte de grupos juveniles de la parroquia y desde muy pequeños, de la vida comunitaria de sus barrios; participan o lideran procesos en sus comunidades de origen.

El grupo nuestro que es "construyendo futuro" que somos los mismos del teatro, es el que lleva la batuta del centro Afro, somos las que nos encargamos de la biblioteca, de los niños, algunas como Johana o Lina, manejan los grupos de confirmación, somos las que le damos vida al centro Afro. (Zulma, 10 de mayo de 2014, entrevistada por Molina, I., Tumaco)

Estos jóvenes son líderes que desde su intuición y apoyados por los sacerdotes de las parroquias locales (pero sin adscribirse a un proyecto político específico) han logrado configurar acciones colectivas en beneficio de la comunidad, enfocados en la generación de espacios alternativos y lúdicos para jóvenes y niños de diferentes barrios.

Bueno ya no somos del grupo juvenil sino somos coordinadores de procesos juveniles de la pastoral juvenil, digamos las Arañas del grupo del Teatro por la paz, y lo que hacemos es que ya coordinamos otros grupos juveniles, con la compañía de Uli, que es la encargada de la pastoral juvenil, con ella coordinamos grupos juveniles de acá de Tumaco, del barrio Nuevo Milenio y otros barrios cerca y otras veredas cercanas por el mar como la Caleta, 
San Juan de la Costa, como a una hora, media hora, 20 minutos. (Johana, 19 de mayo de 2014, entrevistada por Molina, I., Tumaco)

Estas actividades les han permitido tener reconocimiento en sus barrios y en la parroquia. Ahora ya se han involucrado en otros procesos pastorales, con instituciones de la sociedad civil como las juntas de acción comunal o la casa de la memoria. Su participación con otras organizaciones está enfocada en el apoyo a actividades culturales o deportivas, con el objetivo de promover valores de paz en algunos barrios de Tumaco.

Nosotros llamamos a los que formamos Jóvenes formadores de paz, en otros barrios, en otros colegios, a veces a través del teatro, otras veces a través de cosas que les gusten, por ejemplo yo sé hacer photo shop, yo sé hacer videos, si el vídeo no les gusta bueno vamos trabajando con teatro, también coordinamos procesos con niños pero esos son más que todo artísticos, porque a ellos les gusta más la danza, la música, el bailar, y la catequesis, que la llevamos nosotros para confirmación, con jóvenes. (Johana, 19 de mayo de 2014, entrevistada por Molina, I., Tumaco)

Teatro por la paz se conforma a partir de tres subgrupos, los dos juveniles y el de las mujeres. Desde el comienzo del proceso estuvo orientado por Norma, una voluntaria de nacionalidad alemana quien es docente en teatro y fue la lideresa del proceso hasta 2014. Norma formalizó el grupo de teatro y se ha encargado de hacer un ejercicio de transferencia con los participantes. La idea es que los conocimientos teatrales, administrativos y de gestión se queden en la comunidad, por eso Mary Cruz se ha ido empapando de esta labor y asumió el liderazgo a partir de 2015.

Dentro del grupo se han establecido reglas que les permiten a los participantes fomentar relaciones de amistad y de confianza, a partir del respeto a las diferencias. Otro acuerdo es que la toma de decisiones se valida en lo colectivo, es decir, todos los integrantes tienen que ver con las decisiones que se producen dentro del grupo. Y aunque el liderazgo recaiga en un par de personas, las decisiones relacionadas 
con todos se avalan en público; así se fortalece un sentido de pertenencia y de protagonismo entre los integrantes.

Las decisiones son colectivas, si es un problema entre todos pensamos y decidimos, la mayoría es por democracia, pero también un poquito con la razón, a veces no es solo lo que pensamos, sino que también buscamos opiniones externas, y si el problema es de teatro buscamos a alguien que no tenga nada que ver con el teatro, para tener otro punto de vista. (Johana, 19 de mayo de 2014, entrevistada por Molina, I., Tumaco)

Además, el grupo también se nutre de la participación de personas externas que contribuyen con consejos o con aportes concretos en cuanto al montaje de las obras. Esta ha sido una práctica recurrente en la historia del grupo. Al inicio del proceso, existían tres grupos de teatro, como se mencionó anteriormente, pero dadas las condiciones de los participantes las presiones de la violencia que producen en la realidad tumaqueña unas condiciones particulares y también como una forma de fortalecer el proceso, hubo una fusión de los tres grupos y ahora es uno solo, que produce, monta y presenta las obras.

Bueno cada grupo hacía su obra y cada grupo la presentaba en la semana por la paz, un grupo en tal iglesia, otro en tal iglesia y no nos tropezábamos ninguno. Luego en el 2010 para mi otro yo, como era el homenaje a la hermana Yolanda Cerón, todos los tres grupos hicimos la misma obra, y así había personas que tenían los mismos papeles, y si iban pa' Satinga y yo no puedo ir, llevaban a Yolanda de Araña que vaya, o no, no está el vivo, traigan al vivo del otro grupo, ahí empezamos a intercalarnos, hasta que después ya las obras las presentábamos todos, entonces todos participábamos. (Johana, 19 de mayo de 2014, entrevistada por Molina, I., Tumaco)

Esta integración permitió generar nuevos vínculos entre los participantes; se configuró un nuevo grupo, se tejieron nuevos lazos de confianza y un proceso intergeneracional de crecimiento personal y de creación colectiva que se manifiesta no solo en los vínculos que existen como 
organización, sino también en las obras, lo que permite ampliar talentos, posturas y concepciones variadas, pero integradoras sobre el tratamiento de la violencia en su apuesta estética.

Ya como desde el tercer año para acá, empezamos como esa fusión de Tumatai con los jóvenes, y esa fue una fusión bonita que a la vez dio buenos resultados, y hasta hoy la relación de los jóvenes con las Tumatai ha sido una relación de respeto, de confianza, de acompañamiento, ellos las ven como el grupo de las mujeres mayores que los acompañan, eso en cuanto a la relación personal, de respeto mutuo, siempre ese respeto, esa delicadeza y ese amor con que nos tratamos, y lo más importante es que ellos no se aburren en compartir, al contrario, les gusta. (Mary Cruz, 23 de mayo de 2014, entrevistada por Molina, I., Tumaco)

El grupo de Teatro por la paz mantiene varias relaciones con instituciones públicas de la región como la Diócesis de Tumaco, con sus parroquias, la comisión diocesana de Justicia y Paz, el Centro Afro y algunas instituciones educativas, con las que se han establecido jornadas de capacitación en teatro para los jóvenes escolarizados de algunos barrios y sectores aledaños. Además, es reconocido por diferentes ONG regionales e instituciones nacionales de diferente orden, por su labor entre los jóvenes, y ha sido beneficiario de diferentes procesos de capacitación para continuar con su labor por parte del Ministerio de Cultura y el Centro de Memoria Histórica. Asimismo, ha podido presentar en diferentes escenarios locales, regionales y nacionales los montajes y ha obtenido diferentes reconocimientos por su trabajo. Esto demuestra que como organización han podido establecer diversos vínculos con otras entidades, que les han permitido visibilizar su labor y obtener beneficios de formación para la continuidad del proceso.

Una tensión en el grupo tiene que ver con el tipo de temas que trabajan en las obras, es decir, hay una movilización fuerte de sentimientos, de energías y de elementos psicológicos que afectan a los participantes; además, porque muchos también son víctimas directas de la violencia y conocen de primera mano las secuelas psicológicas 
de los hechos violentos que se recrean en las obras y que son reflejo de la realidad tumaqueña.

Esto es una carga emocional muy fuerte, me acuerdo cuando terminamos la semana por la paz del año pasado, yo tenía pesadillas, Alicia tenía pesadillas, sentían que las violaban, la mayoría del grupo sentía pesadillas, hasta Norma, se sentía como las víctimas, es que se mueven muchos sentimientos. (Nohora, 20 de mayo de 2014, entrevistada por Molina, I., Tumaco)

Para contrarrestar esto, al final de cada semana de la paz, que es justamente la época más fuerte en cuanto a presentaciones, se busca generar un ambiente de recogimiento, de autocuidado, para compartir y relajarse, para que los integrantes del grupo puedan organizar sus emociones y tramitarlas positivamente, a nivel individual y grupal.

\section{Corporación Pasolini en Medellín: en los límites de la realidad visual}

La mayoría de los pasolinis son profesionales de Ciencias Sociales; de ahí que uno de los intereses latentes de este grupo sea ampliar el discurso y la mirada académica en función de realidades sociales concretas que son muy complejas, a partir de las cuales es posible diluir las fronteras disciplinares. Esta experiencia es una forma concreta de aplicar la lógica del conocer a una realidad específica, pero que no se limita a un discurso, sino que busca una transformación social; es decir, explorar otras narrativas: lo audiovisual en una perspectiva crítica de las ciencias humanas.

Además de los jóvenes que iniciaron el proceso en la UDEA, actualmente hacen parte del grupo algunos beneficiarios de proyectos que luego se integraron, lo que amplió los vínculos entre agentes y organizaciones sociales o de base con las cuales se trabajó temporalmente. En la corporación hay un grupo base que constituye la junta administradora, que es periódica. Estos son los líderes que están pendientes de que el trabajo de la corporación sea permanente. Hay otro grupo de participantes que se juntan por proyectos, y su vinculación inicial 
es a través de propuestas investigativas o de producción, lideradas por el grupo base. El grupo base está conformado por una junta de cinco personas, que asumen un papel administrativo durante un tiempo definido; organización que promueve el trabajo en equipo, tanto en la producción como en la participación en convocatorias.

En cuanto a la circulación de sus productos audiovisuales, no hay aún una estrategia muy definida en este sentido; se busca que circule libremente entre las comunidades protagonistas inicialmente y en canales de Internet o para quien desee verlos. La corporación participa activamente en festivales locales, regionales o nacionales y concursa para proyectos futuros.

Un punto interesante de su trabajo es el tipo de articulación que tienen con organizaciones de base, con las que se busca establecer posibilidades de cooperación o intercambio de servicios en función de los intereses de cada entidad, esto sobre todo con algunas organizaciones juveniles con las que han trabajado. "Alguien llega y dice vea yo tengo esta idea, ah pues hagámosla, hagamos un intercambio de servicios pues; con los muchachos hemos hecho intercambio de servicios de cosas [...]" (Germán y Wicho, 24 de marzo de 2014, entrevistados por Molina, I., Medellín).

En este colectivo juvenil la amistad es el motor principal que relacionó a cada uno de los integrantes de la corporación Pasolini en Medellín. Así, los vínculos de confianza, cooperación y reciprocidad se establecen no solo desde la corporación (es decir, a partir de proyectos o del desempeño particular), sino además desde motivaciones de orden personal como la amistad, la cercanía de intereses, la posibilidad permanente de socialización y creación, además de compartir o negociar formas de pensar el contexto y, especialmente, la pasión o el gusto por lo audiovisual.

Estas motivaciones que tienen que ver con lo personal, con la atmósfera de sentimientos, pasiones y condiciones particulares que se configuran en la amistad o el compartir son definitivas para continuar y mantener el proceso. Este tipo de camaradería ha llamado a algunos beneficiarios de proyectos a que posteriormente hagan parte del grupo. Esta es una característica intangible fundamental para que las organizaciones funcionen, especialmente las juveniles, a partir del sentimiento 
de "parche" y de compartir con compañeros los intereses o pasiones particulares que permiten otra posibilidad de exploración y de creación.

Una de esas pasiones centrales para la gente de la corporación es la producción audiovisual pensada como un camino y un fin que permite expresar sus narrativas y, a través de la creación audiovisual, “desarmar mentes en la ciudad de Medellín”. Este sueño surgió con ocasión de una tesis de pregrado en 2004 en la UDEA (Arango y Pérez, 2004), que buscaba aplicar la antropología audiovisual a una realidad concreta.

A medida que fue pasando el tiempo, estos jóvenes encontraron en el gusto por el cine, la cercanía académica, las clases, el cine club o el grupo de investigación al que pertenecían la excusa perfecta para consolidarse como grupo y conformar así la corporación. En sus orígenes se puede ubicar una intencionalidad académica, pero que debate con ese mismo lenguaje y las formas de pensamiento parceladas o disciplinares. Los jóvenes de ese entonces buscaron innovar en sus disciplinas: la antropología y la sociología.

Se puede inferir que los que hoy hacen parte del colectivo coinciden en el interés por la creación audiovisual; sin embargo, el gusto es lo que prima a la hora de hacer un proyecto, pues se van generando ideas a partir de articular los intereses de los participantes, no solo en lo que tiene que ver con los lenguajes audiovisuales, también en el tipo de temas por trabajar, en el proceso esperado, en la perspectiva disciplinar o en el tipo de mensaje que buscan. Es así como la organización es ante todo un espacio de negociación y creación colectiva donde caben los diversos gustos e intereses de los participantes. De esta manera, la experiencia de lo colectivo o grupal se configura como un ámbito que potencia experiencias y saberes (entre otras cosas), que produce un tipo de agente dispuesto a negociar y a vincularse en ambientes de reciprocidad y creación como germen de lo político.

En cuanto a las relaciones con otras entidades, estas se pueden analizar en dos sentidos. Como se mencionó antes, se fundamenta en cooperación sobre todo con organizaciones de base de las comunidades con las que establecen redes de trabajo temporales, especialmente con las juveniles o con organizaciones no gubernamentales que también trabajan temas artísticos, de hip-hop y que hacen parte de 
las comunas donde han trabajado, a las cuales llegan por vínculos de amistad o contactos personales.

Otro vínculo fuerte es con la UDEA, justamente porque la mayoría de los integrantes son egresados de ahí y su cercanía se construyó en la universidad. De hecho, algunos de ellos son docentes o estudiantes de la Universidad, y el vínculo con esta institución también tiene que ver con la financiación, pues algunos de los proyectos están relacionados con esta, bien por financiación o como requisito académico.

Igualmente, la vinculación con la academia tiene que ver con el nivel de análisis e innovación que la corporación propone en cada uno de sus productos o procesos. Teniendo en cuenta que todos son profesionales de las Ciencias Sociales, el tipo de narrativas empleadas es reflejo de un proceso reflexivo y analítico, lo que les ha permitido un reconocimiento no solo en esta universidad, sino también en otras instituciones académicas que trabajan la antropología y la comunicación, gracias a lo cual se han articulado a grupos o proyectos de investigación, publicar artículos o capítulos de libros y ampliar el tipo de socialización de sus logros en redes académicas a nivel nacional e internacional.

Por otro lado, también se pueden ubicar las relaciones que establecen con la institucionalidad (Alcaldía y otras dependencias gubernamentales-privadas de Medellín) para la financiación de proyectos en diferentes comunidades.

El nivel de relación con otras organizaciones se va configurando dependiendo de las necesidades del grupo, y esto tiene que ver con la satisfacción de necesidades de orden económicas (en el caso de la institucionalidad) y con las comunidades de base a partir de la posibilidad de asociación temporal para cada proyecto; pero también con entidades académicas para fortalecer aprendizajes en relación con diversas formas de hacer y de pensar la producción audiovisual o la antropología visual.

\section{A modo de cierre}

Con este panorama, es posible comprender cómo la autonomía se hace presente en las experiencias presentadas. Para empezar, se puede 
afirmar que la autonomía es fruto de un ejercicio reflexivo consciente frente a lo cotidiano, sobre el tipo de reglas o formas específicas que establece la sociedad para instituir horizontes de acción y de significación. Sin embargo, es en la subjetividad donde empieza a tener sentido esa idea de autoreflexión, idea que se va articulando a una concepción de identidad, en este caso grupal, a partir de la cual la autonomía empieza a materializarse en el discurso y en el hacer.

En el caso de estas experiencias, es necesario destacar la reflexividad frente a lo cotidiano, a las prácticas que implican el desempeño de estos agentes en los ámbitos privado y público; es ahí donde cobra importancia preguntarse: ¿qué espera la sociedad de mí?, ¿qué tipo de agente soy?, ¿qué es lo que me interesa desarrollar como ser político?, ¿mi acción qué sentido tiene en este presente?, ¿qué es lo que quiero cambiar del entorno donde existo?, ¿lo que hago para subsistir es suficiente?, ¿qué tipo de relaciones quiero para mi existencia? Y necesariamente esto tiene una implicación colectiva cuando estas organizaciones se preguntan: ¿qué realidad queremos crear para nuestras vidas?, ¿hay espacios para "nosotros” como grupo?, ¿qué prácticas o discursos no queremos legitimar?, ¿qué tipo de prácticas nos interesa posicionar?, ¿qué impacto tiene esto para la sociedad?

Así, la autonomía es fruto de un proceso consciente de autoexploración y reflexividad por parte de los agentes comprometidos con su acción, que devela un posicionamiento discursivo y político del yo que tiene necesariamente una implicación colectiva; es decir, como iniciativa subjetiva contiene implícito un horizonte colectivo que busca posicionarse y articularse significativamente en las prácticas sociales. En otras palabras, no se queda solo en lo singular, sino que tiene un ciclo de proyección que únicamente tiene sentido en las interacciones con otros, es decir, en la intersubjetividad.

Castoriadis advierte que el sujeto existe en una heteronomía instituida que lo determina, pero su horizonte de realización se enfoca hacia la autonomía como proyección de su existencia, posibilidad inagotada de poner todo en paréntesis, y a partir de ese ejercicio permanente articularse en la intersubjetivad y construir un discurso propio, un accionar que esté encarnado de sentido, que posibilita un espacio 
y un tiempo que le permitan al agente ejercer su autonomía, pero esta siempre tiene al fin de cuentas una condición colectiva de realización.

La autonomía no es eliminación pura y simple del discurso del otro, sino elaboración de este discurso, en el que el otro no es material indiferente, sino cuenta como contenido de lo que él dice, por lo que una acción intersubjetiva es posible y no está condenada a quedarse como vana, o a violar por su simple existencia lo que plantea como su principio. (Castoriadis, 1988, p. 183)

Así, para poder hablar de autonomía es necesario comprender el encuadre histórico social donde transcurre la acción. En el caso de estos grupos, de la Corporación Pasolini en Medellín y de Uno entre mil, encontramos un nivel de autonomía en el siguiente sentido:

- Los dos grupos establecen un horizonte propio, es decir, no hay mediación de un tercero que anime su acción. Son los propios interesados los en su momento decidieron juntarse voluntariamente para deliberar sobre el porqué y para qué de cada agrupación. Definieron el sentido del grupo, lo discutieron y echaron a andar una propuesta construida colectivamente que recoge el pensamiento y la voluntad de los participantes.

- Definen criterios de autoorganización, de administración y de empoderamiento para ser eficientes en función de las metas planteadas. Establecen reglas y formas de relación que constituyen acuerdos voluntarios que se mantienen y que regulan las relaciones internas. Establecen formas particulares de denominarse, que se van alimentando de la experiencia, de los logros y las dificultades que determinan la vida del grupo.

- Crean contenidos propios en cuanto a identidad, formas de relación con otras organizaciones o de no articulación, y establecen límites. Asimismo, configuran elementos simbólicos que tienen una función específica en cada sesión, cada producto o proyecto, a partir de los cuales se otorga sentido a la acción por medio 
de rituales o de las formas particulares de hacer las cosas en función de los tiempos, lógicas e intereses de los participantes.

- Configuran formas propias de liderazgo, que surgen a partir de la organización definida colectivamente, es decir, este es asumido por los participantes en diferentes momentos y se fortalece o se modifica a medida que el grupo se va consolidando.

Y en los tres casos se puede entender que:

- Mantienen presente una actitud problematizadora frente a su entorno inmediato, al contexto donde su acción es pertinente. Esto implica un ejercicio de cuestionamiento permanente, de buscar alternativas diferentes a la lógica instituida, a construir estrategias propias, caminos inéditos que implican creatividad o una lógica propia de acción como en el caso de Uno entre Mil; de imprimir una postura no convencional a través del juego para definir y concebir todos los aspectos de la organización. Ese ejercicio reflexivo permanente condiciona su horizonte y las prácticas validadas en el interior de cada organización en función de una coherencia entre lo que se piensa y se hace, lo cual los posiciona en su entorno y los hace merecer reconocimiento en la comunidad en la que se desenvuelven.

- Asumen al antagonismo como una instancia activa y permanente que configura su acción, de tal forma que afecta la producción de contenidos, los acuerdos, los propósitos y la existencia misma de la organización a la que pertenecen en función de expresar unas ideas, unas necesidades no resueltas y unas lógicas diferentes a la impuesta por la heteronomía social. Como en el caso de Pasolini en Medellín, que apela a una forma diferente de pensar el entorno, de penetrar en la realidad en la apuesta por sensibilizar a través de la imagen que amplía las perspectivas, que supera a las tradiciones, que desborda lo real. 
- Deciden crear experiencias dentro del grupo que se oponen al imperativo social, sin que esto implique su negación, pero buscando transformarlo de una forma eficiente y creativa, como en el caso de Teatro por la paz, desde las carencias, asumiendo las dificultades y el riesgo de manifestarse públicamente, pero con una actitud de resistencia y de acción permanente en función de la transformación del pensamiento, en contra de condiciones aparentemente naturalizadas en el imaginario social.

En este último aspecto quiero detenerme un poco, dado que parte del interés por comprender cuáles son las lógicas a partir de las que se produce la autonomía para estos agentes es justamente distinguir cuál es su apuesta en términos de institución, en el sentido de que la problematización consciente y permanente a la que responde su acción necesariamente está vinculada a una intención legítima de configurar su entorno inmediato, como una posibilidad concreta de operar en los procesos de fundación de la realidad social en la que estos agentes se pueden vincular, a partir de su escala de acción.

Es decir, la autonomía es una manifestación clara de subjetividades instituyentes que al agruparse necesariamente desembocan en la institución de nuevas prácticas, de otros imaginarios, de otras formas posibles de comprender e intervenir lo social y esto es lo que Castoriadis entiende como la interminable tensión entre instituido e instituyente.

Lo anterior, debido a que supone un movimiento permanente de construcción de sentido que inicia en lo subjetivo, pero que se va articulando a cadenas de significaciones y representaciones que definen las reglas y las formas particulares que estructuran lo social. Esto necesariamente está enmarcado en una lógica social-histórica que determina, condiciona y da vida a lo colectivo. Así, la autonomía se erige entonces como punto nodal para la transformación, empezando porque va introduciendo en las representaciones otros contenidos, otros significantes e imaginarios frente a las formas de interpretación, de organización, de producción de sentido y de construir posibilidades de empoderamiento, es decir, orienta la transformación de la sociedad en función de la autonomía como empresa colectiva. 
Esta apuesta es una proyección de lo político como una condición necesaria y permanente en ese movimiento abierto de una sociedad instituyente. Es una puesta en evidencia de la posibilidad inacabada de instituir sentido y de apertura de lo social a partir de acciones específicas.

Estas experiencias dan cuenta de agentes que hacen uso consciente del poder que reside en cada uno, y que encuentra una vía de materialización concreta a partir de la posibilidad de autonomía que existe en sus prácticas, en su reflexión hacia el exterior que los constituye, hacia las relaciones sociales que los posiciona y hacia el sendero que estiman pertinente en función del interés particular de transformar su entorno inmediato.

Un sujeto autónomo es aquél que se sabe con fundamentos suficientes para afirmar: esto es efectivamente verdad, y esto es efectivamente mi deseo. La autonomía no es pues, elucidación sin residuo y eliminación total del discurso del otro no sabido como tal. Es instauración de otra relación entre el discurso del Otro y el discurso del sujeto. [...] El sujeto es también actividad, pero la actividad es actividad sobre algo, de lo contrario no es nada. (Castoriadis, 1988, pp. 178 y 179)

Así las cosas, esta es la posibilidad de darse a sí mismos un destino de acción concreto a través de la participación activa en estos grupos; los jóvenes de estas experiencias están haciendo un uso consciente de su poder, que deliberadamente se constituye como apertura hacia la transformación activa de su vida, su subjetividad, su identidad, su entorno; esto en el proceso intersubjetivo a partir del cual estructuran su discurso y su acción antagónica específica.

El poder que están configurando en su quehacer es explícito, se nombran, se autodefinen y se configuran como actores sociales activos que tienen que ver con la fundación de lo social, es decir, con la activación de nuevos significantes, en este caso con relación a ellos mismos, a su ocupación, a la posibilidad de politizar lo cotidiano, de ejecutar activamente un antagonismo radical ${ }^{11}$ hacia la heteronomía instituida.

11 Radical en el sentido que Laclau le otorga al término, cuando expresa que es actividad consciente y permanente. 
Este poder atraviesa la posibilidad de la autoorganización, de amplificar la potencia de la acción colectiva en función de unos intereses negociados y compartidos grupalmente. Esto induce a establecer lógicas propias de acción, vinculación, sistematización, planeación y evaluación en función del horizonte trazado; hecho que permite ampliar la capacidad de autodeterminación y hacerse partícipes de la organización de su vida y entorno inmediato.

Activar el infrapoder que reside en cada uno de los agentes es una manifestación concreta de la autonomía y permite operar o intervenir directamente en los procesos de fundación de la realidad de los agentes que deciden para sí y para un colectivo; de esta manera, se sobrepasa el cerco de información, de conocimiento y de organización que caracteriza a la heteronomía, y se amplían así los límites de lo decible, lo pensable o lo realizable.

Esta es una ruptura específica con el orden o formas imperantes para determinar su vida. Es en últimas crear un orden diferente al establecido; es redefinir, en el caso de las experiencias narradas, cómo sobrepasar el interés económico de una organización juvenil, es potenciar la condición juvenil como una oportunidad única de crear, innovar, activar otras formas de hacer las cosas, definir su rol como actor político, crear caminos de acción colectiva que tienen un impacto que desborda lo académico, que transita entre lo público o lo privado y que produce unas relaciones diferentes a las predominantes, entre agentes, entre saberes, entre oportunidades y ámbitos de acción.

De ahí la importancia de estas experiencias, por cuanto hacen explícita la autonomía vinculada al territorio, a realidades concretas que afectan y condicionan la vida en comunidad. De esta manera, las experiencias descritas favorecen la construcción colectiva de saberes y conocimiento articulado a sus propias historias de vida, es decir, al contexto histórico social específico que es significativo en los procesos que adelanta cada agrupación y que se vincula, entre otras cosas, con el hecho de deconstruir el imaginario que frente a la condición juvenil aún persiste.

Con lo anterior, no se puede desconocer que este tipo de autonomía es el germen a partir del cual se puede configurar una ruptura con la heteronomía y que transforme conscientemente el ámbito de lo 
público en términos colectivos, pero este es parte de un proceso a escala más grande que implica otros elementos. Pero es solo a partir de este tipo de iniciativas como se empiezan a configurar posibilidades de transformación de lo social; es solo a partir de estas micro realidades que se construye el rompecabezas de una sociedad instituyente.

Y esa creación se hace, como siempre, con un carácter "circular" pues sus elementos se presuponen los unos a los otros y sólo tienen sentido los unos a los otros. Sociedades que se cuestionan a sí mismas quiere decir concretamente individuos capaces de poner en tela de juicio las leyes existentes, y la aparición de individuos tales solo es posible si se produce al mismo tiempo un cambio en el nivel de la institución global de la sociedad. (Castoriadis, 1988, p. 213)

Para ir cerrando, es necesario precisar cuál es la intención de estos jóvenes al apelar a la autonomía como un elemento fundamental de su acción y tiene que ver justamente con instaurar en su grupo y en el entorno algunas prácticas e imaginarios que ubican lo político como uno de los motores de su acción. Esto, en términos de Castoriadis, apunta a generar procesos de institución en los ámbitos simbólicos, significativos y en la acción misma.

En un aspecto simbólico, la construcción de un imaginario sobre lo político empieza inicialmente en la subjetividad y se complejiza en los procesos de socialización en la intersubjetividad, es decir, en la cooperación con otros. Así, la construcción de un imaginario tiene que ver con la producción de sentido, en este caso, frente a lo político. Para estos jóvenes, su trabajo o percepciones sobre su condición y frente a la sociedad no está etiquetada y aislada de la vida cotidiana, es decir, el imaginario que se tiene frente a lo político no hace parte de una esfera especializada de acción que se activa en determinados momentos o escenarios, sino que hace parte integral del quehacer diario, cotidiano, permanente.

Ese imaginario está relacionado con la vida cotidiana y se alimenta de la vida misma, no existe esa escisión que prevalece en la concepción moderna de la política. Asimismo, no requiere intermediarios, en este caso, instituciones o líderes políticos, sino que emerge voluntariamente 
siempre que la subjetividad lo permita, es decir, siempre que exista una intención consciente de transformación de entornos específicos, de articulación con otros y de proyección conjunta de un horizonte compartido con otros. Es un producto de la intersubjetividad, de la negociación permanente con la alteridad.

El campo de acción de lo político habita en todos los sujetos, siempre y cuando estos decidan asumir este compromiso, esta práctica permanente de problematización, de reflexión y de construcción activa de condiciones simbólicas y materiales diferentes a las imperantes.

Es decir, para estos jóvenes la acción de cualquier agente que así lo decida, conscientemente, puede ser significativa al momento de instituir una alternativa a la lógica de la heteronomía; es suponer que el mundo de lo público, de lo colectivo, también se dinamiza con la acción de los que aparentemente no tienen ningún tipo de poder de transformación, siempre que lo medie un ejercicio de consciencia reflexiva que permita producir otros contenidos, otras formas de relación con las prácticas, como apunta Castoriadis (1988): “implica que ese alguien instaura una relación nueva con "su ley", lo cual significa, entre otras cosas, que puede modificarla sabiendo que lo hace" (p. 210).

En cuanto a la acción, en este caso estética, estos grupos recurren a uno de los elementos vitales de la condición humana: la posibilidad de crear, de generar otras formas discursivas que afectan ampliamente a los demás, que producen otras relaciones entre sentidos, contenidos y tiempos, otras condiciones de posibilidad no solo para generar canales de comunicación, sino también posibilidades de vida a través de esta acción. Es la posibilidad de encarnar imaginarios, perspectivas antagónicas y de configurar sentidos "diversos" en un tiempo y espacio concretos, donde lo territorial, lo social, lo cultural, lo económico y lo político están imbricados complejamente en un recurso sensible como el audiovisual, el juego o el teatro.

Otro elemento por destacar tiene que ver con los procesos de significación a los cuales está vinculada la acción de estos agentes sociales, y que se devela en el lenguaje, en la forma como designan su realidad, la resignifican discursivamente y la encarnan en hechos o acciones específicas. Instituyen en sus prácticas otros puntos de vista que van articulando a la red de interacciones sociales en las que se ubican; de 
esta manera, posicionan otros sentidos que se reincorporan a lo social como nuevas significaciones relacionadas con:

- Establecer (en el caso de uno ente mil) la idea del juego como una apertura a un mundo de acción que sobrepasa el acto de jugar, y que reivindica una forma diferente de asumir el hacer en la modernidad, vinculando el horizonte de realización de cada participante. Es decir, reivindicar la idea del juego como un espacio de incertidumbre que pone entre paréntesis la realidad y que permite recrear el presente, reiventar lúdicamente otra realidad, otra posibilidad de conocer-se entre los participantes, de reconocer-se como agentes dotados de acción, de capacidades que son significativas, no solo para cada participante o para el grupo, sino también para la sociedad. En otras palabras, resignificar al acto de jugar y al juego mismo, no como un tiempo de ocio que por lo general se desperdicia, sino como una potencia creadora de realidades particulares que están mediadas por la magia, la palabra, la posibilidad de crear vínculos diferentes. Es una invitación a repensar y transformar la manera como se relacionan entre sí las personas, y configurar así en el acto de jugar otras perspectivas de acción asociadas a lo político, lo pedagógico, lo ambiental y la vida misma.

- En el caso de la Corporación Pasolini en Medellín este proceso es una apuesta por la periferia, por la reivindicación de lo alternativo, de la alteridad a través del discurso audiovisual, para visibilizar y reflexionar sobre la cultura popular, los lenguajes, las estéticas urbanas y las relaciones territoriales que se tejen en las comunas de Medellín. Es la búsqueda por transformar la mirada a partir de la cotidianidad, de construir narrativas propias, de autoobservación y construcción de saberes sobre las prácticas sociales que experimentan las comunidades de estos sectores, especialmente las asociadas a la condición juvenil. Es la apuesta por crear otras formas de comprender, de explorar el territorio y de producir conocimiento desde las ciencias sociales, para ampliar de esta manera la perspectiva no solo 
para la academia, sino también para la misma comunidad del Valle de Aburrá.

- En el caso de Teatro por la paz, se busca a través del teatro incorporar en las prácticas cotidianas aquellos saberes y representaciones que habitan la memoria histórica de esta población, para reinscribirla en la actualidad y pensar-se como una comunidad activa que afronta la violencia y que a pesar de su historial de muerte y marginación es posible reconfigurar el mundo de lo público, construir lazos de cooperación y solidaridad. Además, parte del ejercicio que promueve el grupo es configurar otros conceptos asociados a la condición de víctima, unos más activos que no continúen estigmatizando a los más vulnerables, sino que les permita expresar su dolor, su tristeza y compartir con otros las secuelas de la violencia de una forma segura y digna, y que favorezca otros imaginarios más arraigados en la resistencia, la confianza y la posibilidad de construir un futuro diferente.

- Adicionalmente, también se trata de administrar el poder que reside en cada uno de los agentes de una sociedad, de autonombrarse, de desligarse o vincularse conscientemente a un horizonte de futuro, bien sea existente o uno que aún no tiene nombre, pero que se va consolidando con la acción de cada agente. Como en el caso de Uno entre Mil, cuando sueña una masloka, una comunidad de lualentos; o los jóvenes de Pasolini que deciden acompañar a los muchachos de las comunas que han sido estigmatizados y ampliar los espacios u oportunidades para configurar sus propios intereses, alejados de la visión asistencialista que conduce a perpetuar las mismas prácticas de exclusión e inequidad. O como los jóvenes de Tumaco, que creen en el teatro como un dispositivo que potencie sus capacidades de expresión, de creatividad y de oportunidad de vida para otros jóvenes con talento, con carisma y con avidez de oportunidades diferentes a las que ofrece la sociedad actual. Es 
decir, estos jóvenes están haciendo uso del infrapoder, como señala Castoriadis (1989), que reside en ellos como agentes capaces de acción transformadora, que tiene implicaciones directas en su entorno inmediato, pero también en la construcción de significaciones asociadas a su acción, a partir de las cuales estructuran nuevas relaciones, otros sentidos, y proyectan otros caminos de acción que dinamizan lo social.

Con lo anterior es posible afirmar que estos grupos, al hacer despliegue de autonomía con su organización y con las reglas o estrategias que implementan para la continuación de su proceso, lo que están generando son procesos vinculantes entre ellos y su comunidad, procesos de comunicación e intersubjetividad exitosos en la consecución de sus objetivos o de acción colectiva en diferentes episodios de la historia grupal; también están produciendo valores, formas de existir, significaciones que se materializan en contenidos específicos frente a la capacidad de gestión y de organización que poseen los jóvenes, frente a la generación de prácticas "sencillas o simples" que están dotadas de sentido y que van produciendo otros valores como la cooperación, la confianza, la capacidad de negociación con la diferencia, la reciprocidad y el florecimiento de lo político en cada una de sus acciones, deliberadas e investidas de autonomía.

Estos contenidos están proponiendo otras formas posibles de organización, de acción y articulación entre lo público y lo privado, entre la historia y el presente, entre los lenguajes académicos y los populares, entre el cultivo de sí y la responsabilidad contenida en cada agente, entre el disfrute y la acción política, entre las prácticas heredadas y la invención de otras formas de existir y transformar el entorno inmediato. Estos son los contenidos que están configurando estos grupos en su accionar, en su discurso, en las prácticas que establecen y que los identifican en el sistema al que pertenecen.

Estos grupos invitan a pensar la autonomía como motor de transformación, como una forma vinculante que privilegia a lo político como epicentro vital de nuevas relaciones sociales, de nuevas relaciones con la institucionalidad, con las reglas que determinan quiénes pueden modificar el presente y quiénes no, o cómo construir un entorno 
diferente donde el interés particular se incorpore y contribuya a definir otras interacciones que tengan sentido en la construcción de lo cotidiano y lo común. 



\section{Conclusiones}

Finalmente, después de este recorrido, en estas conclusiones se desarrollan tres aspectos que recogen el ejercicio de investigación. El primero tiene que ver con puntualizar los aspectos que son centrales para comprender lo político a partir de las experiencias analizadas, como una condición fundamental para entender los procesos que constituyen lo social, a partir de los cuales se establecen acuerdos e imaginarios que producen normas y prácticas; pero que también constituyen formas de acción, de enunciación y de transformación permanente en el seno de las comunidades, como una manifestación inequívoca de la condición inacabada de lo social, pero también como categoría primigenia de la condición humana. Posteriormente se argumenta por qué es necesario ocuparse de entender esta condición de lo político en las sociedades contemporáneas, en función del tipo de agentes en los que me interesó comprender esta categoría. Finalmente, se esbozan los retos que implica para las ciencias sociales atender este tipo de transformaciones de lo social por vía de lo político.

\section{Lo político, en las prácticas analizadas}

La intención de esta investigación fue repensar lo político a partir de prácticas estéticas específicas de jóvenes, comprender cómo 
entienden lo político en su quehacer y proponer algunos elementos teóricos que permitan generar marcos de interpretación a partir de los cuales repensar lo político y la política, y de esta manera lo social, en tiempos cuando todo cambia, todo se renueva y pareciera que lo político pierde importancia.

A lo largo del documento se ha argumentado que las experiencias estéticas propuestas por estos grupos son manifestación de lo político, que lo producen, lo adaptan y a partir de ahí adquieren sentido unas prácticas que pareciera que están desconectadas de una pretensión política, o que se circunscriben a un interés particular que nada tiene que ver con la constitución de lo común. Sin embargo, Teatro por la paz, Uno entre mil y la Corporación Pasolini en Medellín nos demuestran que no es así, que su impacto en la construcción de un imaginario de lo político es importante y que para estos agentes se convierte en una forma específica de modificar su presente y construir otro futuro posible. En función de esto, se recorren algunos elementos importantes por destacar:

- Lo político es una manifestación de autonomía, que surge en la búsqueda de identidad y en la generación de elementos que articulen una acción colectiva, que produzca elementos específicos que caracterizan unas subjetividades, acciones o prácticas concretas. Castoriadis (1988) afirma que no hay autonomía sin revolucionar la manera de pensar y el contenido de los pensamientos, de ahí que esta se produzca inicialmente en la subjetividad, a partir de pasiones, afecciones o situaciones particulares, que ubica al agente en relación con unas coordenadas históricas y territoriales específicas, a partir de las cuales estas orientaciones de autonomía tienen sentido.

- La autonomía es fundamento de lo político, pues la transformación del mundo es una apuesta que se anida en la subjetividad, que se materializa en el discurso y en la acción. Es ante todo una ruptura con lo establecido, que genera o produce nuevos contenidos asociados a otras prácticas o significados de lo común, de lo público. Por tanto, es la apertura a 
nuevas posibilidades de institución a partir de la creación de contenidos, de espacios, de saberes. En estas experiencias, la autonomía tiene una manifestación específica en sus formas de gestionar o configurarse como grupo, así como en las experiencias estéticas que recrean, porque es justamente en estas donde se hace más evidente esa apuesta por la creación de contenidos, de movilizar representaciones e imaginarios en torno a lo colectivo, al territorio, a la forma de articular lo común. Se puede afirmar que en estas experiencias la autonomía estética tiene que ver con vincular mundos desligados en la acción y el discurso, entre lo privado y lo público, entre la acción transformadora y la "apatía”, y así reivindicar otros modos de argumentación que son igualmente válidos, porque apelan a un régimen de significación diferente al logos, que permite ampliar su capacidad de expresión, desbordar los significados atribuidos a ciertas prácticas e instituir, por qué no, otra lógica de pensamiento y acción.

- Lo político es escenario y producto del antagonismo, el cual se constituye como un elemento central y altamente productivo; es solo a través de este como se hacen evidentes los límites de lo social. Y es justo en ese momento cuando esos límites se pueden dislocar, porque se ponen en tensión otros regímenes de significación opuestos a los instituidos, resignificando estos marcos o demarcaciones que limitan la acción colectiva. El asunto es que el antagonismo implica creatividad, despliegue de acciones, de argumentos, de visibilización de intereses y agentes. Si se logra activar como horizonte de acción es muy productivo, porque es ahí donde se producen torsiones o transformaciones en las formas de la experiencia política, y la aparición de otros agentes que la encarnan; con esto hay vínculo con la trama de lo social y se producen comunidades de sentido. Este es el caso de los grupos analizados, que a partir de sus intereses particulares o sus pasiones se confrontan con unos imaginarios que terminan limitando su identidad, su forma de ser e involucrarse 
en lo público. Por eso incorporan en su práctica estética un posicionamiento o cuestionamiento frente a lo instituido, y es a través de este antagonismo como producen unos modos de ser, hacer y pensar que refunda su acción política, que los vincula de una forma diferente con sus pares o sus vecinos, con las políticas públicas, con las instituciones, con su entorno; aspectos que posibilitan ubicarse como actores sociales copartícipes en la construcción de comunidad, pero también de lo público, y que además amplían su protagonismo en lo social.

- El antagonismo como exterioridad que moviliza y cuestiona lo instituido, en lo discursivo, pero también en la praxis, es fundamental dar cuenta de los diversos intereses o divisiones de lo social, haciendo explícito que la sociedad y los grupos humanos no son homogéneos. Eso que se denomina como "el pueblo" es diverso, o como sucede en este caso los jóvenes no son una categoría homogénea, y es en el reconocimiento de la diferencia donde se puede comprender al antagonismo como un detonante del proceso social de construir lo común.

- Otro elemento relevante de las experiencias consultadas es el relacionado con el tipo de acción colectiva que experimentan estos grupos; qué dificultades han tenido para articularse, para confrontarse, para producir socialmente otros valores, otros sentidos, otros discursos. Como se intentó demostrar, estos grupos son ante todo un espacio de convergencias, de intereses que se articulan desde lo cotidiano, a partir de unos referentes construidos colectivamente en la acción. La construcción como grupo no ha sido una tarea fácil y se ha ido consolidando en su historia particular, en este caso mediada por la experiencia estética como motor de producción colectiva, como medio y fin que dinamiza la acción en términos políticos, con afectación no solo en cada participante, sino también en su entorno, en su escala de acción o de relaciones. 
- Así, lo político se entiende como construcción de vínculos que producen aparición, la cual surge en lo privado, es decir, en lo doméstico, porque en esta esfera se siente el choque entre lo instituido y lo que el agente quiere instituir. Es ahí donde lo impuesto adquiere forma específica y afecta condicionando o limitando al ser en sus intereses o deseos. Por eso, en este ámbito se configura inicialmente lo político como deseo de transformación. Establecer lo político como el ejercicio de aparición en lo público es ampliar un límite que resulta contradictorio, pues lo público se alimenta y produce al calor de lo privado, de lo doméstico. Por su puesto, la posibilidad de aparición se hace explícita en el ámbito de lo público, pues es ahí donde se introduce en el imaginario colectivo como una práctica posible, que sobrepasa límites, pero a la vez los reconstituye; sin embargo, su fuente de aparición está en lo inasible de lo privado, como pensamiento y en el vínculo de lo doméstico.

- Para estos grupos, es ahí donde reside la fuerza de su acción colectiva, que se produce con el cemento de la amistad, de la confianza, de la reciprocidad, del compartir entre pares; sin esa filigrana intangible de lo cercano ningún grupo o colectivo podría desarrollarse como tal, y este es un proceso que surge con el tiempo, en la experiencia compartida que posibilita el desarrollo del potencial de cada agente y genera así un horizonte compartido, construido conjuntamente, en la diferencia y la cercanía territorial y en la forma de percibir la realidad. Esa es justamente una potencia de estos grupos, pues se producen en un vínculo que se modifica permanentemente, y de esta manera se ajustan a los condicionamientos del entorno, pero se mantienen fuertes con la acción colectiva y con la capacidad de vínculo que despliegan sus participantes.

- Así, la construcción de vínculos pasa por un ejercicio singular y a la vez colectivo; se produce en los afectos inicialmente, en el seno de experiencia compartida a través de la cotidianidad, 
de la capacidad de reciprocidad o de confianza que se concreta en la agremiación, en la generación de horizontes compartidos, que se hacen visibles en el plano de lo público con unas características propias que los identifican y posicionan en relación con otros. Esta condición se produce en el reconocimiento de lo diverso, del otro, con el cual contar, construir, discutir y establecer horizontes conjuntos de acción.

- Sin embargo, esa constitución de vínculos como proceso comunicativo es cambiante, pues se circunscribe al entorno, a partir del cual se van produciendo unas estrategias, unas formas particulares de acción, unos contenidos, unas máximas que producen sentido compartido y que se alimenta del hacer, del compartir. Es ahí donde el antagonismo tiene sentido, pues este se configura como un modo particular de percibir el entorno y como potencia de acción. De esta manera, el antagonismo como un vínculo que convoca a la acción y la reflexión se posiciona a manera de elemento central para comprender lo político.

- Lo político solo se produce por la acción determinada y consciente de agentes colectivos. En este caso, la atención se centró en los jóvenes, como agentes que operan reordenamientos y relaciones entre regímenes de significación a través de su apuesta estética, como manifestación de lo político. Se puede afirmar que estos jóvenes que conforman Teatro por la paz, Uno entre mil y la Corporación Pasolini en Medellín ante todo se reconocen como agentes de cambio, como coproductores de su realidad, pues participan activamente a partir de su campo de acción para transformar su vida, modificándose recíprocamente, con autonomía, pero también reconociendo las implicaciones privadas y públicas que esto significa para sí y su entorno.

- Por eso, asumen también el riesgo y el compromiso de trabajar con otros, de articularse y constituirse como agentes colectivos, desde la diferencia, asumiendo las tensiones que esto implica, 
pero conscientes de que es una alternativa (la mejor con la que cuentan) para poner a jugar sus intereses, su talento, su capacidad de liderazgo y trasformación. Las y los jóvenes consultados se asumen como agentes que producen actos y discursos que modifican su mundo, pero que también los modifican, los hacen corresponsables de su identidad, de su antagonismo e inconformidad.

- Con todo esto, no se puede hablar de un sujeto joven único, pues las condiciones que definen a los jóvenes también se han ido modificando. Ya no solo es la condición de edad o el ciclo vital, o el segmento del mercado que representan, sino también de las prácticas de precarización a las que se ven sometidos, de innovación e incertidumbre con las que se reconoce al joven en la actualidad, la condición mutable de su identidad, o la dificultad para acceder a las esferas donde se construye la democracia. En últimas, los y las jóvenes se siguen transformando, y en este estudio se pueden asumir como agentes con potencia de transformación singular y colectiva. El papel de los jóvenes en la constitución de lo común es muy relevante, como vimos en estas tres experiencias; es un reconocimiento que hay que tener como referente para suponer transformaciones sociales, la constitución de vínculos, de discursos y construcción de nuevos sentidos sobre lo público.

- A partir de esta investigación se puede afirmar que los jóvenes que hacen parte de estos grupos son ante todo agentes de inconformidad y de acciones que producen otras formas de existencia, de reflexión y acción, de generación de acontecimientos que impactan en la cotidianidad de comunidades ancladas a un espacio y un tiempo concretos. Esto se da gracias al discurso, a su capacidad de enunciación a través de sus prácticas estéticas, las cuales se caracterizan por ampliar las formas de percepción de lo social, al incluir en su cotidianidad otras cosmovisiones, otras convenciones que sugieren la mutabilidad de lo instituido, 
la modificación de lo real, la constitución de nuevos significados a través de la imaginación y la creatividad.

- De ahí que gracias a la manifestación de su inconformidad sean acreedores de reconocimiento, de visibilización, y son protagonistas para entender cómo en la actualidad se produce lo social, cómo se anima y cómo se produce otra realidad, otros lenguajes, discursos, prácticas, que hacen falta para construir no solo transformaciones, sino también otras categorías para reflexionar y animar dichos cambios.

- Otro elemento importante que se puede resaltar de estos grupos es el hecho de concebir la experiencia estética como principio de acontecimiento, a partir de la cual se va configurando un "nosotros" diferente al instituido, con unas lógicas y unos matices singulares, que va construyendo nuevos vínculos para existir en comunidad, para producir principios rectores de acción y de relación; en últimas, la constitución de comunidades de sentido, que puedan reconfigurar lo común. Así, la experiencia estética se establece como experiencia productora de sentido, de nuevos lenguajes y ordenes de lo cotidiano, que propone un espacio o un tiempo que, aunque se inscribe en unas coordenadas específicas, apela a una percepción diferente de este, fuera de los marcadores espaciales o temporales convencionales, donde se pone entre paréntesis lo instituido, las representaciones de lo social aceptadas colectivamente o la misma certidumbre de la cotidianidad. Dado que es en ese espacio donde se reflexiona o se cuestionan los límites de lo social, las prácticas discursivas y vida normalizada, desde otras lógicas o regímenes de significación, operados por diversas prácticas discursivas y narrativas, concebidas desde una intencionalidad explícita que interpela al sujeto, sus acciones y los imaginarios a los que se ha acogido como ciudadano. La experiencia estética propende a una construcción contingente, diversa e inédita de lo social, 
que hace parte de las relaciones sociales y configura otras posibilidades instituyentes de comprender y vivir en comunidad.

- Esta condición de productividad de lo social, asociada a la experiencia estética, se consolida cuando se analiza que en los grupos consultados los contenidos, las narrativas, las metáforas y las procesos de enunciación se vinculan a territorios y a tiempos específicos, es decir, la apuesta estética que adelanta cada grupo se alimenta de su entorno; es ahí donde su pretensión se articula a la constitución de transformaciones cognitivas y específicas de la prácticas en comunidades reales, donde la potencialidad asociada a estas experiencias construye saberes y prácticas nuevas que se validan en la cotidianidad, y que potencian las habilidades y el talento de agentes específicos que asumen diferentes roles en el seno de cada comunidad, y quienes en estas prácticas estéticas reconocen otras formas de productividad afiliadas a la creatividad y al poder de la expresión mediada por lo sensible, por el teatro, el juego o el audiovisual, es decir, ampliando formas de enunciación y significación.

- Así, las experiencias estéticas que se analizaron permiten vincular diferentes regímenes de expresión y representación, que configuran prácticas inéditas de pensamiento, discurso y acción, las cuales están vinculadas a un territorio, a un tiempo real y simbólico donde transcurre lo común, las historias compartidas; donde se establecen y reconocen antagonismos, agentes y relaciones siempre cambiantes que producen lo cotidiano, incluyendo nuevos contenidos, reflexiones y prácticas que terminan resignificando lo común.

- En consecuencia, la experiencia estética como constructora de acontecimiento está ligada estrechamente a una interpretación de lo político, como ese momento de contingencia que introduce o produce cambios, que no se deriva de estructuras previas, sino que se vincula más a la idea de imaginación, de creación, 
porque altera los espacios y los tiempos de lo cotidiano, y con ello las representaciones, imaginarios o significaciones del mundo que habitamos y de la carga de sentido que esto implica.

- Lo político es el espacio real de acción del agente contemporáneo, porque se aplica a su espacio vital, a su propio entorno y a las relaciones en las que se ubica, dado que el mundo de la política se presenta como un espacio simbólico mediado por la representación y por la certeza de que es un ámbito donde el agente del común no tiene ningún tipo de acceso o de implicación, excepto en el momento de avalar a un candidato. Así las cosas, resignificar lo político como un espacio real de acción de los agentes es redimensionar y dotar de sentido la vida cotidiana, y reasignarle al agente su capacidad de acción, de asociación, de enunciación, de antagonismo, de discurso y capacidad de transformación que reside en la condición humana, y que actualmente pareciera disminuida y a veces extinta o vaciada.

- Reconocer en lo político ese ámbito propio de acción que se configura en lo privado y afecta lo público, que se construye individual y asociativamente, pero que es fundamental para dinamizar la vida cotidiana y las prácticas sociales, es incorporar a agentes como los jóvenes con su capacidad y potencia de acción, de transformación en el mundo de lo público, de reconocerlos, como apunta Rancière (2011), como actores de lo común y no solo individuos privados.

Ahora bien, ocuparse de lo político es fundamental porque, en primera medida, lo político crea horizontes de sentido a través de procesos de acción-reflexión de lo social, del entorno inmediato de los agentes, de su propia vida. Es decir, lo político crea modos de acción o formas de manifestación diversos y su finalidad es instituir sentido que dinamiza lo social. Esto implica un ejercicio de síntesis, de reflexión que pasa por el reconocimiento de las formas de ordenamiento social en las que se ubica el agente; es decir, las formas de poder que condicionan su existencia, y así producir antagonismos conscientes, activos 
que produzcan nuevas relaciones, manifestaciones o acciones específicas que transforman subjetividades en contextos específicos.

Ligado a lo anterior, es necesario reconocer esos modos o formas de manifestación diferentes, a partir de las cuales se producen significados que se vinculan al entramado de sentidos que instituyen lo social y que a la larga van modificando cognitivamente y en el discurso los imaginarios sobre prácticas, creencias y agentes a parir de su capacidad de acción transformadora.

En segunda instancia, se puede inferir que lo político crea ordenamientos simbólicos, los cuales se incorporan contingentemente a través del discurso en los imaginarios sociales y modifican acciones concretas, lenguajes, saberes y conocimientos. Estos ordenamientos operan fundamentalmente en el lenguaje y el discurso, como elementos constitutivos de toda significación y por ende de toda estructura social, los cuales producen prácticas específicas y van simultáneamente afectando la constitución del agente, la potencia de su accionar y su desempeño en lo público.

Los ordenamientos simbólicos operan en la generación de identidades y subjetividades en torno a la constitución de actores colectivos que producen sentido a partir de su experiencia compartida, del establecimiento de senderos de acción y contenidos que nutren sus prácticas. Así es como se van produciendo variaciones de sentido a partir del posicionamiento subjetivo de estos agentes en su entorno, de la inclusión de otras representaciones que configuran su realidad, las cuales sustentan su apuesta estética que busca deconstruir los relatos instituidos y ampliar las formas de renombrar su realidad e incluir otros significantes y sentidos de lo social.

Un tercer elemento por destacar es que lo político crea tensiones entre la política y lo instituido, porque surge como antagonismo a esas formas de institución que la política produjo, con unos modos y lenguajes específicos de ejercer o someterse al poder; es decir, "la circunscripción de una esfera particular de experiencia, de objetos planteados como comunes y que responden a una decisión común" (Ranciere, 2005, $\mathrm{p}, 18)$. Lo político entonces se configura como un ámbito paralelo que surge en el seno de lo instituido con la función precisa de irrumpir ese orden, esa distribución de roles, de espacios y de tiempos que animan 
lo público o lo privado, y que introducen así nuevas prácticas, con lo cual se visibilizan otras lógicas de acción y reflexión, nuevos antagonismos o disensos.

En otras palabras, la política es un campo simbólico de acción, de institución de normas, de acuerdos, que se nutre de lo político como un movimiento inacabado y permanente que funda, que visibiliza y amplía los límites, pero que simultáneamente introduce otros discursos que producen lo social.

Del mismo modo, lo político crea articulaciones sociales que se van incorporando con el tiempo a escalas de acción más amplias, pero que parten de la posibilidad de otorgarle nuevos significados a las prácticas sociales. Es una apertura a otras modalidades de acción colectiva, a nuevas formas de producir trabajo u ocupaciones, resignificando oficios, tradiciones y prácticas estéticas o culturales que parecieran simples, aisladas o poco significativas para el desarrollo humano y la reserva cultural de una comunidad; una apertura a la generación de nuevas formas de construir conocimientos o saberes de lo social, lo comunitario, la convivencia, la legitimidad de lo legal y su repercusión e impacto en lo cotidiano y construcción de lo común.

Dichos entramados sociales se hacen presentes al momento de configurar colectivamente comunidades de sentido en torno a experiencias estéticas diversas, las cuales van fortaleciendo redes de vínculos y saberes que involucran lo afectivo, las pasiones, la creatividad, el compartir como esencia de su quehacer. Esto va produciendo otras formas de articulación, nuevos repertorios y contenidos de la acción colectiva, que no pretenden homogenizar agentes, sino justamente construir en la diferencia, como principio de vinculación social.

Entendido desde una perspectiva de larga duración, estas aperturas de sentido que van produciendo los agentes en sus prácticas crean realidades, discursos, procesos de subjetivación y acciones específicas, que tendrán un impacto potencial entre los participantes y en la sociedad; en este caso, en las comunidades implicadas, las cuales se manifiestan a través de valores como la solidaridad, la cooperación, la reciprocidad, la confianza y la acción como potencia capaz de modificar el presente, al cuestionar la realidad, reelaborando contenidos y acciones que transforman el entorno inmediato. 
Por otro lado, quisiera decir que cuando esta propuesta empezó, uno de los interrogantes que surgió fue: ¿qué propuesta le están haciendo los jóvenes a los Estados, a los dirigentes y a la sociedad frente al cambio que la política requiere? Esto puede pensarse como una permanente invitación a continuar indagando, analizando y acompañando procesos sociales en los cuales los jóvenes hagan presencia, porque su manifestación e inquietud frente a lo que la sociedad establece es de por sí una manifestación de lo político, en el sentido en que hay una permanente inquietud por probar otras salidas, otras formas, otros lenguajes, por vincular ámbitos que aparentemente no tienen nada que ver, como las pasiones, los talentos, las aficiones en el ámbito de lo público. Esta es tal vez una de las propuestas al mundo de la política, al ampliar los escenarios y las formas de vincularse a lo común, al ámbito de la deliberación y la esfera pública a partir de antagonismos activos, que convoquen otras formas de expresión que permitan ampliar los límites de lo decible, de lo visible, de lo negociable.

Otro aporte está relacionado con la potencia que encierra el arte, el mundo de la estética, de la expresividad mediada por las sensaciones y el cuerpo, los afectos, las pasiones y todas aquellas manifestaciones que exaltan la belleza, el gusto y el disfrute como un motor esencial para configurar otros sentidos de la acción política, otras formas de relacionarnos y construir vínculos que no están condicionados solo por una estructura de gobernabilidad, sino también por un principio de contingencia y acontecimiento que potencie movilidades y transformaciones en el ámbito de lo público y lo privado, en la concepción de una comunidad territorial y de sentido que acoja las diferencias, no solo como forma de expresión, sino como lógica de pensamiento, convocando a la diversidad y a la convivencia en la diferencia.

Por esta razón, los grupos analizados no tienen la pretensión de promover ideologías hegemónicas, porque reconocen justamente la situación dinámica y cambiante de lo social; no obstante, entienden que en su discurso se interpelan elementos significantes que modifican el presente, el aquí y el ahora, con lo cual le otorgan sentido a su acción como agentes de cambio que tienen juego en lo social. Es esto lo que hay que examinar, lo problemático de su apuesta de transformación, cómo se produce, de qué recursos o medios se valen para materializa, 
cómo se logra dicha transformación, tanto en ellos como en sus comunidades, cómo mantienen el ejercicio creativo de conectar mundos simbólicos a partir de experiencias estéticas específicas, cómo articulan sus planes de vida a proyectos colectivos, cómo sobreviven y por qué se mantienen.

En consecuencia, uno de los retos para las ciencias sociales es analizar a profundidad la trascendencia e importancia de estos microprocesos, pues tienen una implicación directa al momento de analizar los cambios estructurales, los movimientos sociales, la acción colectiva y los procesos de transformación de lo político y la política. Porque es ahí donde los repertorios, los discursos, las subjetividades y las prácticas transformadoras adquieren sentido, en su vinculación con espacio-tiempo específicos, con agentes reales y con escalas de acción diferenciadas que se articulan contingentemente en lo cotidiano.

Este tipo de análisis hace explícita la importancia de comprender en una escala menor los procesos de organización, de creación, de construcción de sentidos en torno a unas prácticas, a unos procesos que apelan a una sensibilidad y un régimen de significación diferente al impuesto por la contemporaneidad, porque es ahí donde los agentes que experimentan la cotidianidad en un aislamiento explícito con la política y las formas instituidas de ejercer la democracia sienten o experimentan una correspondencia directa con lo común, con lo público, con la búsqueda de alternativas tangibles a un sistema excluyente que fija su atención en lo económico y que subvalora la potencia de generar vínculos diferentes, asociados a lógicas cooperativas y creativas como forma de resistencia, pero también de antagonismo, de autonomía y de transformación concreta de subjetividades, de entornos, de condiciones de vida y promesas de futuro.

Esta es una mina de trabajo comprensivo por parte de aquellos profesionales de las ciencias sociales que se preguntan por qué somos cómo somos, por comprender la construcción del nosotros y por buscar la posibilidad de cambio al modelo de ciudad, de hombre, de desarrollo y de sociedad que prevalece actualmente. Estas experiencias, aunque pequeñas, son muy significativas para los participantes y las comunidades donde se ubican, porque representan un ejercicio valioso de cambio, de florecer de otros poderes, en el sentido de oponerse 
activamente a unas prácticas o formas que son impuestas para todos. De esta manera, se olvida la capacidad de acción del agente, de confrontar los límites y resignificarlos en su vida cotidiana, en su vida pública y privada.

De ahí la importancia de asumir el estudio de este tipo de fenómenos desde la diferencia, no con la pretensión de establecer un marco que estandariza o define a los agentes y los procesos en categorías fijas, sino con la intención de comprender a los fenómenos en su génesis, y con la intencionalidad de contribuir a su potenciación o fortalecimiento.

Para cerrar, vale la pena recordar que el concepto de lo político responde a diversas perspectivas, pero no he encontrado en la indagación realizada proponer de alguna manera un tipo de indicadores o categorías que, más allá de indicar que unos tengan más prevalencia sobre otros, contribuyan a reconocer elementos reveladores al momento de indagar por este concepto. Por su puesto, este es solo un paso en el proceso de construir teoría, así que la puerta queda abierta a otros investigadores para incluir otras variables, como por ejemplo las intensidades con las que prevalece la autonomía, el antagonismo, la posibilidad de aparición, el tipo de incidencia, el tipo de recursos o medios a partir de los cuales se logra expresar la oposición y apuesta de transformación de lo social. La propuesta es preguntarse cuándo, cómo y qué produjo en el grupo y el entorno el hecho de pasar de formas antagónicas a autónomas, o de visibilización y acontecimiento; de cómo afecta la subjetivación, cómo contribuye a la generación o modificación de condiciones específicas, en diferentes escalas. Es ahí donde el tránsito podría arrojar nuevos datos que aporten a comprender lo político en entornos específicos, y que amplíen perspectivas de las sociedades contemporáneas y las alternativas que ellas mismas encarnan para su movilización.

Este fue de alguna manera el propósito que siempre acompañó al proceso y que se convierte en un reto mayor para las ciencias sociales, porque no se trata solo de combinar apuestas teóricas, sino también de atender este tipo de fenómenos sociales tan vigentes hoy en día, por vía de lo político, en perspectiva de la contingencia y la interdisciplinariedad. Creo que en parte esto se logró en este ejercicio porque la 
búsqueda no fue adscribirse a una sola apuesta teórica, sino articular categorías, revisar posturas y vincularlas al análisis a partir de las realidades o necesidades de las experiencias consultadas. En esa labor se integraron autores y conceptos de diversas disciplinas, desde la filosofía política, la comunicación, la estética, el psicoanálisis, la psicología política y la ciencia política. Sin embargo, se logró un diálogo interdisciplinar que permitió comprender unas realidades complejas que todavía me siguen interrogando y que me invitan a continuar explorando otros matices, otras intensidades y, por encima de todo, seguir pensando que los cambios que todos soñamos se originan en este tipo de experiencias, en los barrios, en los espacios de encuentro, con las pasiones y los deseos de agentes comunes y corrientes que tienen claro que la única forma de cambiar el mundo empieza por cambiarse a sí mismos, su entorno inmediato. Desde ahí todo es posible. 


\section{Referencias}

Acosta-Silva, D. y Muñoz, G. (2012). Juventud digital: revisión de algunas aseveraciones negativas sobre la relación jóvenes-nuevas tecnologías. Revista Latinoamericana de Ciencias Sociales, Niñez y Juventud, 10(1), 107-130.

A la Deriva. (2004). A la deriva por los circuitos de la precariedad femenina. Madrid: Traficantes de Sueños.

Agapito, R. (2008). Prólogo. En C. Schmitt. El concepto de lo político (pp. 2-17). Madrid: Alianza.

Aguilera, O. (julio-septiembre, 2010a). Cultura política y política de las culturas juveniles. Utopia y Praxis Latinoamericana, 15(50), 91-102.

Aguilera, O. (abril, 2010b). Acción colectiva juvenil: de movidas y finalidades de adscripción. Nómadas, (32), 81-97.

Aguilera, O. (abril-junio 2012). Repertorios y ciclos de movilización juvenil en Chile (2000-2012). Utopia y Praxis Latinoamericana, 17(57), 101-108.

Ahmad, F., Rahim, S. A., Pawanteh, L., Ahmad, A. L. et al. (noviembre, 2012). Social citizenship: rights, participation and responsibilities of young people. Asian Social Science, 8(5), 132-140.

Albornoz, M. (2010). Blogs, artefactos y política. Iconos, (37), 65-74.

Alvarado, S. y Castillo J. (2010). Colombia: una aproximación a su estado del arte desde mediados del siglo XX. En S. Alvarado y P. A. Vommarco (Comps.), Jóvenes, cultura y política en América Latina: algunos trayectos 
de sus relaciones, experiencias y lecturas (1960-2000) (pp. 231-262). Buenos Aires: Consejo Latinoamericano de Ciencias Sociales [Clacso].

Alvarado, S., Botero, P. y Ospina, F. (julio-septiembre, 2010). Subjetividades políticas: sus emergencias, tramas y opacidades en el marco de la acción política. Mapeo de 61 experiencias con vinculación de jóvenes en Colombia. Utopía y Praxis Latinoamericana, 15(50), 39-55.

Alvarado, S., Ospina-Alvarado, M. y García, C. (enero-junio, 2012). La subjetividad política y la socialización política, desde las márgenes de la psicología política. Revista Latinoamericana de Ciencias Sociales, Niñez y Juventud, 10(1), 235-256.

Alvarado, S., Patiño, J. y Loaiza, J. (julio-diciembre, 2012). Sujetos y subjetividades políticas: El caso del movimiento juvenil Álvaro Ulcué. Revista Latinoamericana de Ciencias Sociales, Niñez y Juventud, 10(2), 855-869.

Alvarado, S. y Vommaro, P. A. (Comps.) (2010). Jóvenes, cultura y política en América Latina: algunos trayectos de sus relaciones, experiencias y lecturas (1960-2000). Buenos Aires: Consejo Latinoamericano de Ciencias Sociales [CLACSO].

Ander-Egg, E. (1995). Técnicas de investigación social. Buenos Aires: Lumen.

Arango, G. y Pérez, C. (2004). Pasolini en Medellín, apuntes para una etnografía audiovisual y sobre la periferia urbana (Tesis de grado). Medellín: Universidad de Antioquia [UDEA].

Arendt, H. (1974). La condición humana. Barcelona, Seix Barral.

Arendt, H. (1993). ¿Qué es la política? Barcelona: Paidós.

Arce, T. (abril, 2010). Resistiendo al establishment desde una propuesta gótica. Nómadas, (32), 135-147.

Arias, M. (junio-diciembre 2010). La ciencia equívoca. Sobre el estudio científico de la política. Revista de Investigaciones Políticas y Sociológicas, 9(2), 75-89.

Barrera, M. y Salgado, S. (enero-junio, 2012). Ciudadanías y competencias ciudadanas. Estudios Políticos, (40), 53-75.

Bayer, R. (1965). Historia de la estética. México, D. F.: Fondo de Cultura Económica.

Becerra, G. (octubre-diciembre, 2011). Las propuestas de Ian Hacking y Judith Butler sobre lo socialmente construido. El caso de la "juventud" en la mirada sociológica. Nómadas, 32(4), 1-17. 
Benedetti, M. (1995). El olvido está lleno de memoria. Buenos Aires: Suramericana.

Bermúdez, E. (julio-septiembre, 2000). El desanclaje de la política. Espacio Abierto, 9(3), 355-364.

Bermúdez, E., Martínez, G. y Sánchez, N. (enero-abril, 2009). Las jóvenes y los jóvenes universitarios en Venezuela: prácticas discursivas y construcción de representaciones de identidades políticas. Cuadernos del CENDES, 26(70), 69-97.

Bolzan, N. (septiembre, 2010). Young people's citizenship. Women in Welfare Education, 9, 50-62.

Bonvillani, A. (abril, 2010). Jóvenes cordobeses: una cartografía de su emocionalidad política. Nómadas, (32), 27-43.

Bonvillani, A. (abril-junio, 2012). Roma y Maxi: dos biografías de militancia. Utopia y Praxis Latinoamericana, 17(57), 75-89.

Boron, A. (2001). Teoría y filosofía política. La tradición clásica y las nuevas fronteras. Buenos Aires: Consejo Latinoamericano de Ciencias Sociales [CLACSO].

Boron, A. y De Vita, A. (2002). Teoría y filosofía política. La recuperación de los clásicos en el debate latinoamericano, Buenos Aires: Consejo Latinoamericano de Ciencias Sociales [CLACso].

Botero, P., Pinilla, V. y Lugo, N. (enero-junio, 2011). Narrativas del conflicto sociopolítico cultural de jóvenes en seis contextos locales de Colombia. Revista Latinoamericana de Ciencias Sociales, Niñez y Juventud, 9(2), 97-126.

Botero, P., Vega, M. y Orozco, M. (julio-diciembre, 2012). Relaciones intergeneracionales: implicaciones en procesos de formación política en jóvenes. Revista Latinoamericana de Ciencias Sociales, Niñez y Juventud, 10(2), 897-911.

Botero, P. (abril-junio, 2012). Investigación y acción colectiva “IAC". Una experiencia de investigación militante. Utopía y Praxis Latinoamericana, 17(57), 31-47.

Bueno, R. (diciembre, 2010). Schmitt: a Crítica Liberal a través do Político. Reflexión Política, 12(24), 60-67.

Castellanos, J. (2011). La condición juvenil: opciones metodológicas para la construcción de un objeto de conocimiento. En G. Muñoz (Ed.), Jóvenes, culturas y poderes (pp. 161-187), Bogotá: Siglo del Hombre Editores. 
Castillo, J. y Castillo, A. (abril-junio, 2012). La red juvenil de Medellín: un ejemplo de nuevas prácticas políticas de los jóvenes en Colombia. Utopia y Praxis Latinoamericana, 17(57), 91-100.

Castoriadis, C. (1983). La institución imaginaria de la sociedad. Barcelona: Tusquets.

Castoriadis, C. (1986). Los dominios del hombre: las encrucijadas del laberinto. Barcelona: Gedisa.

Castoriadis, C. (1988). Los dominios del hombre: las encrucijadas del laberinto. Barcelona: Gedisa.

Castoriadis, C. (1997). Un mundo fragmentado. Buenos Aires: Altamira.

Castoriadis, C. (2000). La exigencia revolucionaria. Madrid: Acuarela libros.

Carrillo, L. (2003). La humanidad, entre la barbarie y la civilización. Tomas Hobbes o el concepto de lo que debería ser la política. En F. Cortés y F. Carrillo (Eds.), Los clásicos de la filosofía política (pp. 211-233). Medellín: Universidad de Antioquia [UDEA].

Cerda, H. (1998). Los elementos de la investigación social. Bogotá: El Búho.

Cerbin, M. y Rodríguez, A. (abril, 2010). La nación latin kings, desafíos para repensar lo nacional. Nómadas, (32), 117-134.

Contreras, C., Correa, F. y García, L. (enero-junio, 2005). Participación política no convencional: culturas de protesta vs. culturas institucionale. Polis: Investigación y Análisis Sociopolítico y Psicosocial, 1(1), 181-210.

Corporación Memoria y Saber Popular (s. f.). Etnografía visual y ficción: apuntes sobre la Corporación Pasolini en Medellín. Crónicas Ciencias Sociales. Recuperado el 12 de mayo de 2015, de http://www.saberpopular. org/index.php?option=com_content\&view=article\&id=220:etnografia-visual-y-ficcion-apuntes-sobre-la-corporacion-pasolini-en-medellin\&cati$\mathrm{d}=44$ :cronicas-ciencias-sociales\&Itemid $=241$

Cortés, F. (2003). La política y la violencia en el pensamiento de Nicolás Maquiavelo. En F. Cortés y L. Carrillo (Comps.), Los clásicos de la filosofía política (pp. 205-237). Medellín: Universidad de Antioquia.

Cubides, H. (abril, 2010a). Trazos e itinerarios de diálogos sobre política con jóvenes contemporáneos de Bogotá. Nómadas, (32), 59-80.

Cubides, H. (2010b). Participación política y organización de jóvenes en Colombia vista desde la tensión "plan de organización-plan de consistencia". En S. Alvarado y P. A. Vommarco (Comps.), Jóvenes, cultura y política en América Latina: algunos trayectos de sus relaciones, experiencias y 
lecturas (1960-2000) (pp. 113-136). Buenos Aires: Consejo Latinoamericano de Ciencias Sociales [Clacso].

Cubides, H. y Guerrero, P. (Eds.) (2013). Trazos e itinerarios políticos de jóvenes, Bogotá: Universidad Central.

Chávez, A. y Poblete, L. (diciembre, 2006). Acción colectiva y prácticas políticas juveniles. Última Década, (25), 144-161.

Delgado, R. y Arias, J. (noviembre-diciembre, 2008). La acción colectiva de los jóvenes y la construcción de ciudadanía. Revista Argentina de Sociología, 6(11), 272-296.

Dallanegra L. (2003). El sistema político latinoamericano. Reflexión Política, 5(10), 7-31.

De Albeniz, I. (2005). Usar la palabra política en vano. Blasfemia, parodia e ironía como reapropiaciones de lo político. Foro Interno, (5), 13-35.

De la Vega, E. (2010). Psicoanálisis y política. Patologización de la infancia pobre en argentina. Revista Latinoamericana de Ciencias Sociales, Niñez y Juventud, 8(1), 67-86.

Díaz, A. (junio, 2005). Representaciones sociales juveniles sobre la democracia. Reflexión Política, 7(13), 180-191.

Díaz, A. y Salamanca, L. (abril-junio, 2012). Los jóvenes son sujetos políticos... a su manera. Utopía y Praxis Latinoamericana, 17(57), 109-118.

Domínguez, M. y Castilla, C. (enero-junio, 2011). Prácticas participativas en grupos juveniles de ciudad de la Habana. Revista Latinoamericana de Ciencias Sociales, Niñez y Juventud, 9(1), 141-160.

Echeverría Reina, L. (2012). Prácticas de resistencia y construcción de ciudadanía en Tumaco: estudio de caso del proyecto educativo teatro por la paz desde los marcos de acción colectiva (Tesis de maestría). Bogotá: Pontificia Universidad Javeriana.

Escudero, M. (mayo-agosto, 2009). La práctica artística como generadora de sujetos políticos. Una lectura de Jacques Rancière. Argumentos, 22(60), 27-38.

Estrada, M. (diciembre, 2007). Política en Hannah Arendt. Estudios Sociales Nueva Época, (2), 137-158.

Farrán, R. (2010). Filosofía y Estado: la dimensión política de la práctica filosófica (en Agamben, Nancy y Badiou). Nómadas, 27(3), 115-123. 
Feixa, C. y Campanera, M. (julio-septiembre, 2010). La vida universitaria y el Plan Bolonia: retrato de dos generaciones estudiantiles. Utopía y Praxis Latinoamericana, 15(50), 11-37.

Fernández, L. (2000). La política de Aristóteles. En Grupo Praxis Obras clásicas del pensamiento político (pp. 13-50). Cali: Universidad del Valle.

Fuentes, V. (enero-junio, 2007). De la representación a la autonomía: visibilizando prácticas políticas alternativas en la izquierda chilena. Revista Sociedad Hoy, (12), 29-43.

Galeano, M. (2009). Estrategias de investigación social cualitativa. El giro en la mirada, Medellín: La Carreta.

Galindo, L. (abril-junio, 2012). Política, juventud e Internet: transformaciones y perspectivas de comprensión en América Latina. Utopía y Praxis Latinoamericana, 17(57), 11-30.

Galindo, L. y Acosta, F. (2010). Hacia un estado del arte sobre sentidos y prácticas políticas juveniles en Colombia 2000-2008. En S. Alvarado y P. A. Vommarco (Comps.), Jóvenes, cultura y politica en América Latina: algunos trayectos de sus relaciones, experiencias y lecturas (1960-2000) (pp. 163-204). Buenos Aires: Consejo Latinoamericano de Ciencias Sociales [ClaCso].

Galindo, L., Cubides, J. y Acosta, F. (julio-septiembre, 2010). Política y juventud en la vida universitaria: un estudio de caso. Utopía y Praxis Latinoamericana, 50(15), 71-90.

Gallardo, J. (2005). Diálogo en la república. Polis: Investigación, Análisis Sociopolítico y Psicosocial, 1(1), 57-89.

García, A. (2010). Gilles Deleuze. La ontología menor: de la política a la estética. Revista de Estudios Sociales, (35), 41-52.

Ghiso, A. y Tabares-Ochoa, C. (enero-junio, 2011). Reflexividad dialógica en el estudio de jóvenes y prácticas políticas. Revista Latinoamericana de Ciencias Sociales, Niñez y Juventud, 9(1), 129-140.

Gillman, A. (enero-junio, 2010). Juventud, democracia y participación ciudadana en el Ecuador. Revista Latinoamericana de Ciencias Sociales, Niñez y Juventud, 8(1), 329-345.

Gómez, R. (abril, 2011). Deleuze o devenir Deleuze. Introducción crítica a su pensamiento. Revista Ideas y Valores, (145), 131-149.

González, J. (enero-junio, 2012). (De) construyendo la esfera pública. Juventud y (la otra) cultura política. Revista Latinoamericana de Ciencias Sociales, Niñez y Juventud, 10(1), 147-157. 
Goodman, N., Bastedo, H., LeDuc, L. y Pammett, J. (octubre, 2011). Young canadians in the 2008 federal election campaign: Using facebook to probe perceptions of citizenship and participation. Canadian Journal of Political Science, 44(4), 859-881.

Gupta, A. y Ferguson, J. (2008). Más allá de la "cultura": espacio, identidad y las políticas de la diferencia. Antípoda, 7, 233-256.

Henn, M., Weinstein, M. y Hodgkinson, S. (junio, 2007). Social capital and political participation: understanding the dynamics of young people's political disengagement in contemporary Britain. Social Policy and Society, 6(4), 467-479.

Henao, J. y Pinilla, V. (2009). Jóvenes y ciudadanías en Colombia: entre la politización social y la participación institucional. Revista Latinoamericana de Ciencias Sociales, Niñez y Juventud, 7(2), 1405-1437.

Henao, J., Ocampo, A., Robledo, A. y Lozano, M. (2008). Los grupos juveniles universitarios y la formación ciudadana. Universitas Psychologica, 7(3), 853-867.

Hervás, A. (2010). La gloria y el concepto de lo político en Giorgio Agamben. Revista de Estudios Sociales, (35), 66-77.

Herrera, J. (2009). La comprensión de lo social. Bogotá: Centro Internacional de Educación y Desarrollo Humano [Cinde].

Hoyos, G. y Vargas, G. (1997). La teoría de la acción comunicativa como nuevo paradigma de investigación de las ciencias sociales: las ciencias de la discusión. Bogotá: Instituto Colombiano para la Evaluación de la Educación Superior [ICFEs], Asociación Colombiana de Universidades [Ascun].

Huizinga, J. (2000). Homo ludens. Madrid: Alianza.

Hurtado, D. (abril, 2010). Los jóvenes de Medellín: ¿ciudadanos apáticos? Nómadas, (32), 99-115.

Jiménez, A. (septiembre-diciembre, 2004). Schmitt: el pensamiento filosófico de lo político. Revista Mexicana de Ciencias Políticas y Sociales, XLVII(192), 15-42.

Red Nacional de Mujeres Afrocolombianas-Kambirí. (2013). Mujer negra: arte, cultura e identidad. Santiago de Cali: Publicaciones Ébano.

Kofes, S. (1998). Experiencias sociales, interpretaciones individuales. En Los usos de la historia de vida en las ciencias sociales (pp. 82-101). Bogotá: Universidad Externado de Colombia. 
Kropff, L. (enero-junio, 2011). Debates sobre lo político entre jóvenes mapuche en Argentina. Revista Latinoamericana de Ciencias Sociales, Niñez y Juventud, 9(1), 83-99.

Lanz, R. (enero, 2006). Lo político transfigurado. Estrategias para entrar al mundo postmoderno. Utopía y Praxis Latinoamericana, 11(32), 105-112.

Laclau, E. (1985). Hegemonía y alternativas políticas en América Latina. Buenos Aires: Siglo XXI.

Laclau, E. (2002). Hegemonía y Antagonismo: el imposible fin de lo politico (conferencias de Ernesto Laclau en Chile, 1997). Santiago de Chile: Cuarto Propio.

Laclau, E. (2008). Debates y combates. Por un nuevo horizonte de la politica. Buenos Aires: Fondo de Cultura Económia.

Laclau, E. y Maouffe, Ch. (2004). Hegemonía y estrategia socialista. Hacia una radicalización de la democracia, Buenos Aires: Fondo de Cultura Económica.

López, J. (2007). Lo político, la política y el acontecimiento. Foro Interno, $7,51-76$.

López, W. (mayo-agosto, 2001). Sobre el objeto de los estudios jurídicos: discusión preliminar. Convergencia, 25(8), 61-77.

Lozano, M. y Alvarado, S. (enero-junio, 2011). Juicios, discursos y acción política en grupos de jóvenes estudiantes universitarios. Revista Latinoamericana de Ciencias Sociales, Niñez y Juventud, 9(1), 101-113.

Manrique, C. (2010). (Com)partiendo el secreto, entre la ley y la ficción: (la literatura y lo político en el pensamiento de Jacques Derrida). Revista de Estudios Sociales, (35), 88-100.

Marchat, O. (2009). El pensamiento político posfundacional: la diferencia politica en Nancy, Lefort, Badiou y Laclau. Buenos Aires: Fondo de Cultura Económica.

Mariñez, F. (julio-septiembre, 2004). La política: entre la filosofía y la ciencia. Utopía y Praxis Latinoamericana, 9(26), 49-65.

Martín-Barbero, J. (abril, 2010). Mutaciones culturales y estéticas de la política. Revista de Estudios Sociales, (35), 15-25.

Maureira, S. (julio-diciembre, 2008). De lo épico a lo cotidiano: jóvenes y generaciones políticas en Chile. Revista de Ciencia Política, 28(2), 143-160. 
Mendoza, L. (abril, 2012). Autonomía, solidaridad y reconocimiento intersubjetivo. Claves éticas para políticas sociales contemporáneas. Revista de Estudios Sociales, (42), 13-26.

Mié, F. (julio-diciembre, 2005). Acción y política en la república de Platón. Signos Filosóficos, VII(14), 9-34.

Mier Garza, R. (enero-junio, 2012). Fragmentos sobre la lentitud. Revista Tópicos del Seminario, (27), 147-228.

Mier Garza, R. (2014). Conferencia en Seminario para el doctorado en Ciencias Sociales y la Maestría en Comunicación y política de la UAM-Xochimilco, México.

Missae, N. (abril, 2010). Refazendo a margem pela arte e política. Nómadas, (32), 13-25.

Morfín, C. (enero-junio, 2011). Jóvenes en acciones colectivas y movimientos sociales para redefinir los espacios públicos y las prácticas ciudadanas. Revista Latinoamericana de Ciencias Sociales, Niñez y Juventud, 1(9), 61-79.

Mouffe, C. (1999). El retorno de lo político. Buenos Aires: Paidós.

Muñoz, G. (2006). La comunicación en los mundos de vida juveniles. Hacia una ciudadanía comunicativa (Tesis doctoral). Manizales: Universidad de Manizales, Centro Internacional de Educación y Desarrollo Humano [Cinde].

Muñoz, G. (enero-junio, 2007). La comunicación en los mundos de vida juveniles. Revista Latinoamericana de Ciencias Sociales, Niñez y Juventud, 5(1), 163-181.

Muñoz, G. (2011). La relación de los jóvenes y las jóvenes con la cultura y el poder. En G. Muñoz (Ed.), Jóvenes, culturas y poderes (pp. 43-64). Bogotá: Siglo del Hombre.

Muñoz-López, S. y Alvarado, S. (enero-junio, 2011). Autonomía en movimiento: reflexión desde las prácticas políticas alternativas de jóvenes en Colombia. Revista Latinoamericana de Ciencias Sociales, Niñez y Juventud, 9(1), 115-128.

Navaz, L. (2011). Políticas de representación: Construcción y marketing de nuevas identidades en el espacio político-mediático. Revista de Antropología Social, (20), 229-261. 
Ocampo, A. (enero-junio, 2011). Ciudadanía juvenil, juventud y Estado: discursos de gobierno sobre sus significados. Revista Latinoamericana de Ciencias Sociales, Niñez y Juventud, 9(1), 287-303.

Ocampo, A. y Robledo, A. (enero-abril, 2009). Significados de la política en mundos barriales populares en Bogotá. Revista Cuadernos del CENDES, 26(70), 23-46.

Ocampo, M., Méndez, S. y Pavajeau, C. (2008). Las subjetividades como centro de la formación ciudadana. Universitas Psychologica, 7(3), 837-851.

Orjuela, L. (julio-diciembre, 2007). La compleja y ambigua repolitización de América Latina. Revista Colombia Internacional, (66), 16-35.

Otero, A. (abril, 2010). Jóvenes trabajadores, jóvenes luchadores. Reflexiones sobre experiencias contemporáneas. Nómadas, (32), 163-177.

Padilla, M. y Flores, D. (enero-junio, 2011). El estudio de las prácticas políticas de los jóvenes en Internet. Revista Comunicación y Sociedad, (15), 101-122.

Palacios, M. y Cordero, R. (abril-junio, 2010). Vínculo social, juventud y trasgresión normativa: aspectos conceptuales y metodológicos en el estudio de la cohesión social en América Latina. Latin American Research Review, 45(2), 140-172.

Papacchini, A. (2000). Una lectura del príncipe de Maquiavelo. En Grupo Praxis (Ed.), Obras clásicas del pensamiento político (pp. 73-112). Cali: Universidad del Valle.

Paredes, D. (2012). Historia, contingencia y revolución en la crítica de Hannah Arendt a Karl Marx. En L. Quintana y J. Vargas (Eds.), Hannah Arendt: política, violencia, memoria (pp. 33-45). Bogotá: Ediciones Uniandes.

Pérez-Rodríguez, I. (julio-diciembre, 2012). Identidad nacional y sentidos de los jóvenes sobre su nación. Revista Latinoamericana de Ciencias Sociales, Niñez y Juventud, 10(2), 871-882.

Picotto, D. y Vommaro, P. (abril, 2010). Jóvenes y política: las agrupaciones estudiantiles independientes de la universidad de Buenos Aires. Nómadas, (32), 149-161.

Piedrahita, C. (abril-junio, 2012). Una perspectiva feminista sobre subjetividades blanqueadas y nuevas lógicas de exclusión. Utopía y Praxis Latinoamericana, 17(57), 65-73.

Pineda, H., Cárdenas, M., Parra, L., Picón, J. et al. (julio, 2007). Las representaciones sociales de la política y la democracia. Última Década, (26), 53-78. 
Pinilla, V. y Lugo, N. (enero-junio, 2011). Juventud, narrativa y conflicto: una aproximación al estado del arte de su relación. Revista Latinoamericana de Ciencias Sociales, Niñez y Juventud, 9(2), 35-62.

Pinilla, V. (2007). Significado de lo público para un grupo de jóvenes universitarios (Tesis doctoral). Manizales: Centro de Estudios Avanzados en Niñez y Juventud [CINDE], Universidad de Manizales.

Poratti, A. (1999). Teoría política y práctica política en Platón. En A. Boron (Comp.), La filosofía política clásica: de la Antigüedad al Renacimiento (pp. 17-57). Buenos Aires: Consejo Latinoamericano de Ciencias Sociales [Clacso].

Quintana, L. (2012). Pensamiento y violencia. En L. Quintana y J. Vargas (Eds.), Hannah Arendt: política, violencia, memoria (pp. 49-66). Bogotá: Ediciones Uniandes.

Quintana, L. y Vargas, J. (2012). Hannah Arendt: politica, violencia, memoria. Bogotá: Ediciones Uniandes.

Quintelier, E., Stolle, D., y Harell, A. (2012). Politics in Peer Groups: Exploring the Causal Relationship between Network Diversity and Political Participation. Political Research Quarterly, 65(4), 868-881.

Rabotnikof, N. (septiembre, 2008). Lo público hoy: lugares, lógicas y expectativas. Iconos, (32), 37-48.

Ramírez, C. (2009). Todos son genios: la crítica a la estetización de la acción política en Carl Schmitt. Revista de Estudios Sociales, (34), 59-71.

Ramos, A., Escobar G. y Cruz, C. (mayo-agosto, 2009). Jóvenes, ciudadanía y participación política en México. Espacios Públicos, 12(25), 103-122.

Rancière, J. (1996). El desacuerdo. Política y filosofía. Buenos Aires: Nueva Visión.

Rancière, J. (2005). Sobre políticas estéticas. Barcelona: Universidad Autónoma de Barcelona.

Rancière, J. (2006). Política, policía, democracia. Santiago de Chile: Lom.

Rancière, J. (2011). El tiempo de la igualdad. Diálogos sobre política y estética. Barcelona: Herder.

Reguillo, R. (2007). Emergencia de culturas juveniles. Estrategias del desencanto. Bogotá: Norma. 
Retamozo, M. (mayo-agosto, 2009). Lo político y la política: los sujetos políticos, conformación y disputa por el orden social. Revista Mexicana de Ciencias Políticas y Sociales, LI(206), 69-91.

Ríos, M. (julio-diciembre, 2009). Johan Huizinga (1872-1945): ideal caballeresco, juego y cultura. Revista de Filosofía y Culturas en Diálogo, (21), 3-18.

Romaní, O. y Sepúlveda, M. (mayo-agosto, 2005). Estilos juveniles, contracultura y política Polis, 4(11), 1-17.

Romero, R. (2002), “En torno al Leviatán (1651) de Thomas Hobbes”, en Obras clásicas del pensamiento político, Cali, Universidad del Valle.

Romero, J. (julio-septiembre, 2010). Participación social de la juventud uruguaya en los últimos 20 años. Utopía y Praxis Latinoamericana, 15(50), 117-128.

Rossi, M. y Amadeo, J. (2002). Platón y Aristóteles: dos miradas sugestivas en torno a la política. En A. Boron y A. De Vita (Eds.), Teoría y filosofía política. La recuperación de los clásicos en el debate latinoamericano (pp. 61-73). Buenos Aires: Consejo Latinoamericano de Ciencias Sociales [CLACSO].

Santamarina, C. y Marinás, J. (1999). Historias de vida e historia oral. En J. Delgado y J. Gutiérrez (Coords.), Métodos y técnicas cualitativas de investigación en ciencias sociales (pp. 259-287). Madrid: Síntesis.

Schmitt, C. (2008). El concepto de lo político. Madrid: Alianza.

Silva, D. (2005). Trascendencia e inmanencia del estado moderno: entre la soberanía y las prácticas disciplinarias. Reflexión Política, 7(14), 110-124.

Simões, S. y Alves, R. (julio-septiembre, 2010). Jóvens urbanos, cultura e novas práticas políticas: acontecimentos estético-culturais e produção acadêmica brasileira (1960-2000). Utopía y Praxis Latinoamericana, 15(50), 57-69.

Singer, A. (2002). De Rousseau al Federalista: en busca de un terreno común. A. Boron y A. De Vite (Comps.), Teoría y filosofía politica. La recuperación de los clásicos en el debate latinoamericano (51-60). Buenos Aires: Consejo Latinoamericano de Ciencias Sociales [Clacso].

Taguenca-Belmonte, J. (septiembre-diciembre, 2012). La opinión política de los jóvenes universitarios de Hidalgo, México. Un análisis desde la teoría de campo. Convergencia, 19, (60), 45-77.

Tassin, E. (2012). La manifestación política: más allá del acierto y del fracaso. L. Quintana y J. Vargas, (Eds.), Hannah Arendt: politica, violencia, memoria (3-16). Bogotá: Ediciones Uniandes. 
Turrión, P. (2009). Los muros de Tebas. La política como decisión sobre la vida o Agamben contra Agamben. Nómadas, 24(4), 105-113.

Uribe de Hincapié, M. (2003). Esfera pública, acción política y ciudadanía. Una mirada desde Hannah Arendt. En F. Cortés y L. Carrillo (Eds.), Los clásicos de la filosofía política (pp. 287-313). Medellín: Universidad de Antioquia [UDEA].

Uribe de Hincapié, M. (2009). [Prólogo] en Galeano, M. Estrategias de investigación social cualitativa. El giro en la mirada, Medellín, La carreta editores.

Urquijo, M. (2002). Disertación en torno al discurso sobre el origen y los fundamentos de la desigualdad entre los hombres de J. J. Rousseau. En Grupo Praxis (Ed.), Obras clásicas del pensamiento político (pp. 157176). Cali: Universidad del Valle.

Valderrama, C. (abril-junio, 2008). Movimientos sociales: TIC y prácticas políticas. Nómadas, (28), 94-101.

Valerio, C., Linares, A., Rincón, J. y Dimas, F. (agosto, 2011). Reivindicar para permanecer... expresiones de ciudadanía de un grupo de jóvenes hiphop de la ciudad de Bogotá. Revista de Estudios Sociales, (40), 101-114.

vv.AA. (2002). Obras clásicas del pensamiento político. Cali: Universidad del Valle.

vv.AA. (1999). La filosofía política clásica. De la antigüedad al renacimiento. Buenos Aires: Consejo Latinoamericano de Ciencias Sociales [ClACso].

Vázquez, M. (abril-junio, 2012). Liderazgo y compromiso político desde una mirada diacrónica: una aproximación a tres generaciones de jóvenes militantes en movimientos de desocupados. Utopía y Praxis Latinoamericana, 17(57), 49-63.

Vázquez, M. y Vommaro, P. (enero-abril, 2009). Sentidos y prácticas de la política entre la juventud organizada de los barrios populares en la Argentina reciente. Cuadernos del CENDES, 26(70), 47-68.

Velázquez, C. (septiembre-octubre, 2008). Democracia compleja para nuevos tiempos nublados. El Cotidiano, (151), 75-85.

Villalobos S. (Ed.) (2002). Hegemonía y Antagonismo: el imposible fin de lo político (conferencias de Ernesto Laclau en Chile, 1997). Santiago de Chile: Cuarto Propio.

Vizer. E. (2003). La trama invisible de la vida social. Comunicación, sentido y realidad, Buenos Aires: La Crujía. 
Vukelic, J. y Stanojevic, D. (Agosto, 2012). Environmental activism as a new form of political participation of the youth in Serbia. Sociologija, 54(2), 387-399.

Wallerstein, I. (2004). Las incertidumbres del saber. Barcelona: Gedisa.

Whyte, J. y Schermbrucker, I. (2004). Young people and political involvement in northern Ireland. The Journal of Social Issues, 60(3). 603-627.

Zarzuri, R. (julio-septiembre, 2010). Tensiones y desafíos en la participación política juvenil en Chile. Utopía y Praxis Latinoamericana, 15(50), 103-115.

Zourabichvili, F. (2007). El vocabulario de Deleuze. Buenos Aires: Atuel. 



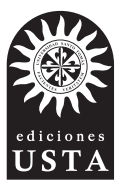

Esta obra se editó en Ediciones USTA, Departamento Editorial de la Universidad Santo Tomás. Se usó papel propalcote de 300 gramos para la carátula y papel bond beige de 75 gramos para páginas internas.

Tipografía de la familia Sabón.

Impreso por Xpress.

2017. 


\section{LO POLÍTICO EN PRÁCTICAS ESTÉTICAS JUVENILES hace}

un reconocimiento explícito a otras formas y abordajes de procesos políticos agenciados por jóvenes, es este caso, a partir del análisis de las prácticas de tres colectivos juveniles que en diferentes zonas de Colombia, con intencionalidades, itinęrarios, repertorios de acción y experiencias estéticas diferentes, potencian la construcción de lo público desde sus territorios y ámbitos de incidencia.

Este libro es producto de una investigación doctoral que presenta la discusión sobre lo que implica pensar las prácticas políticas en la actualidad, partiendo de una mirada clásica que hace evidente las rupturas históricas y teóricas de la política, y ofrece, de esta forma, toda una red conceptual y analítica que posteriormente permitirá la comprensión de otras formas de producción de lo político. A través de estas se expone cómo la experiencia estética posibilita otras explicaciones sobre las formas de construcción social de narrativas y acciones políticas, que no necesariamente se encuentran inscritas en las lógicas institucionales, pero que sin lugar a duda contribuyen a las discusiones actuales sobre los itinerarios de estos agentes en el campo político. 